\title{
Seismic Monitoring at Cascade Volcanic Centers, 2004—Status and Recommendations
}

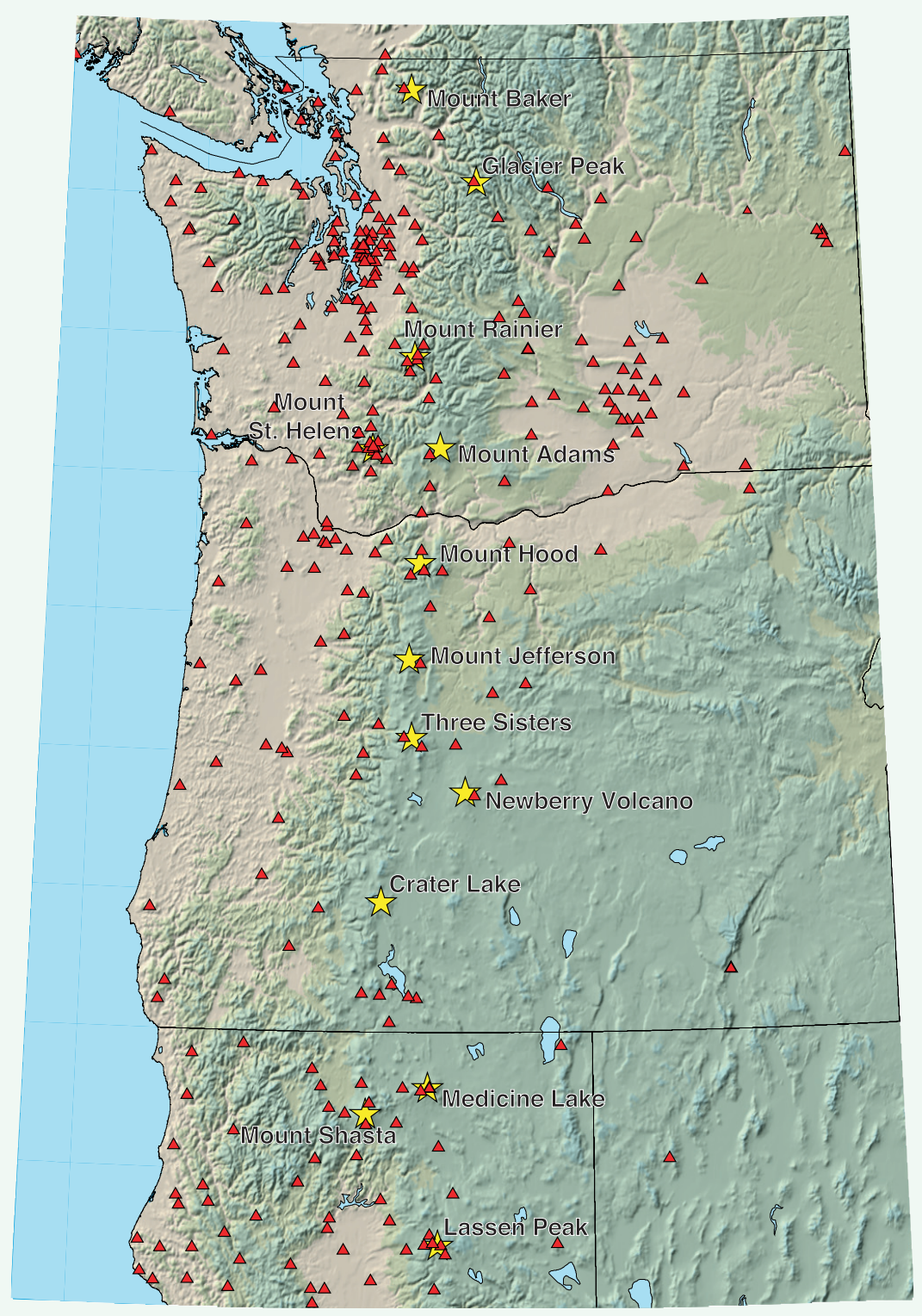

Scientific Investigations Report 2004-5211

U.S. Department of the Interior

U.S. Geological Survey 


\section{Seismic Monitoring at Cascade Volcanic Centers, 2004-Status and Recommendations}

By Seth C. Moran

Scientific Investigations Report 2004-5211 


\section{U.S. Department of the Interior}

Gale A. Norton, Secretary

U.S. Geological Survey

Charles G. Groat, Director

Version 1.0, 2005

This publication is available only online at: http://pubs.usgs.gov/sir/2004/5211/

Manuscript approved for publication, September 30, 2004 Production and design by Stephen L. Scott

Text edited by James W. Hendley II

Any use of trade, product, or firm names in this publication is for descriptive purposes only and does not imply endorsement by the U.S. Government 


\section{Contents}

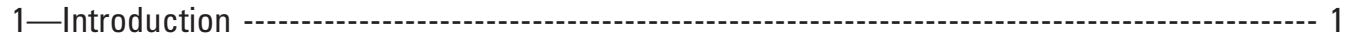

2-Seismic monitoring at Cascade volcanic centers - the big picture ---------------------- 1

3-Seismic networks by volcano --- 1

4-Assessment of the ability of networks to detect anomalous seismicity ------------ 2

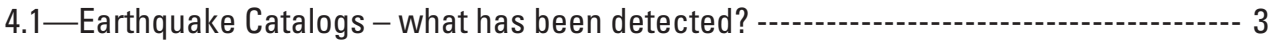

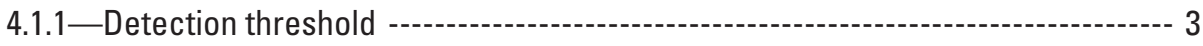

4.1.2-Magnitude of completeness--- 3

4.1.3-Theoretical detection threshold --.-- 7

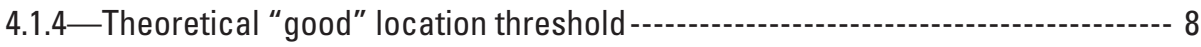

4.2-Important seismic-monitoring criteria other than earthquake detection

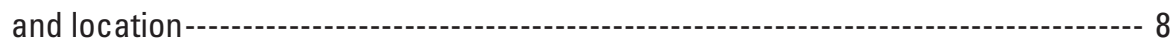

5-Recommendations ------- 16

5.1-Seismic networks should be upgraded before any unrest occurs ---------------- 16

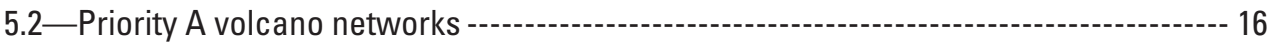

5.2.1—Mount Baker --- 16

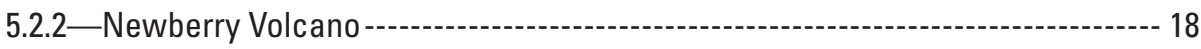

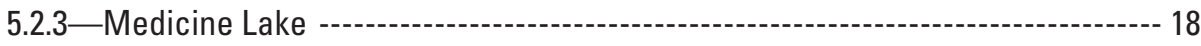

5.2.4-Crater Lake --- 19

5.2.5-Three Sisters --- 19

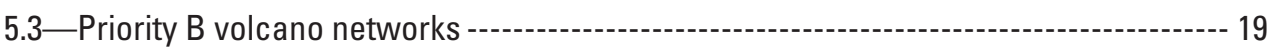

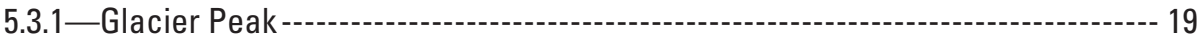

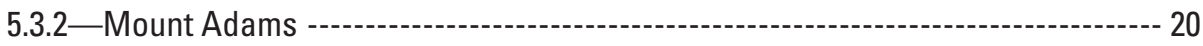

5.3.3-Mount Jefferson --- 20

5.4-Priority C volcano networks --- 20

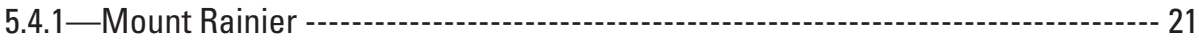

5.4.2-Mount Hood --.-- 21

5.4.3-Mount Shasta --- 21

5.4.4-Lassen Peak --------- 21

5.5-Priority D volcano networks --- 21

5.5.1—Mount St. Helens --- 21

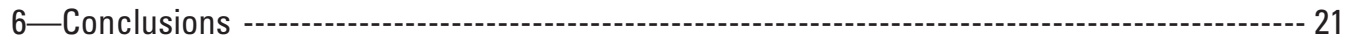

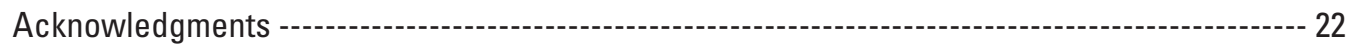

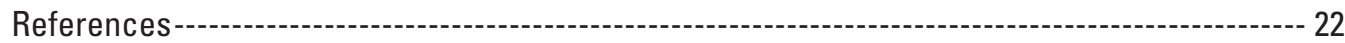

\section{Figures}

1. Shaded relief map showing locations of all seismic stations operating in the Pacific

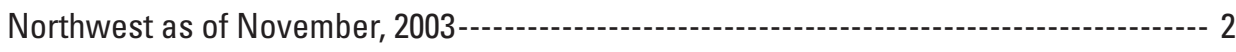

2. Plot showing number of stations within $\mathrm{X} \mathrm{km}$ of 11 Cascade volcanoes ------------------- 3

3. Single-channel seismic-reflection profiles relative to ODP Site 1015------------------ 4

4. Glacier Peak seismic network --- 4

5. Mount Rainier seismic network ---------------------------------------------------- 4

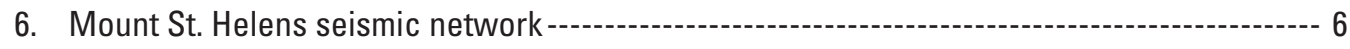

7. Mount Adams seismic network--- 5

8. Mount Hood seismic network--- 5 


\section{Figures-continued}

9. Mount Jefferson seismic network - 5

10. Three Sisters seismic network --- 5

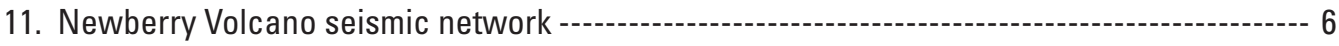

12. Crater Lake seismic network---- 6

13. Mount Shasta and Medicine Lake seismic networks -- 6

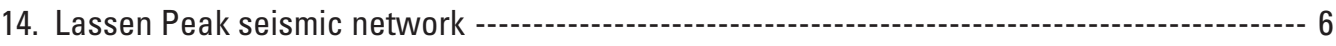

15. Smallest magnitude earthquake within $20 \mathrm{~km}$ of volcano between 1990-2003------------- 7

16. Magnitude of completeness for earthquakes within $20 \mathrm{~km}$ of volcano between

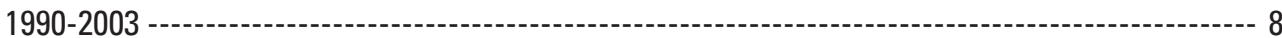

17. Estimates of detection thresholds at the summit of each volcano ----------------------- 9

18. Mount Baker and contours of estimated minimum magnitude for earthquake detection -------- 9

19. Glacier Peak and contours of estimated minimum magnitude for earthquake

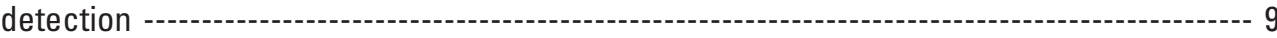

20. Mount Rainier and contours of estimated minimum magnitude for earthquake

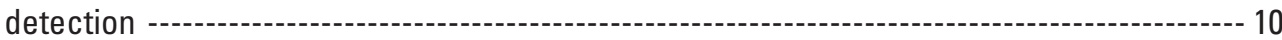

21. Mount St. Helens and contours of estimated minimum magnitude for earthquake

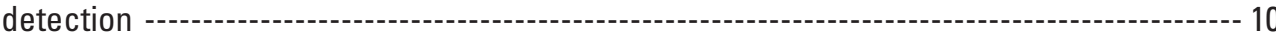

22. Mount Adams and contours of estimated minimum magnitude for earthquake detection ----- 10

23. Mount Hood and contours of estimated minimum magnitude for earthquake detection --------- 10

24. Mount Jefferson and contours of estimated minimum magnitude for earthquake detection -------- 11

25. Three Sisters and contours of estimated minimum magnitude for earthquake detection

26. Newberry Volcano and contours of estimated minimum magnitude for earthquake

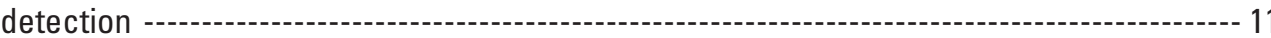

27. Crater Lake and contours of estimated minimum magnitude for earthquake detection

28. Mount Shasta and Medicine Lake contours of estimated minimum magnitude for earthquake detection

29. Lassen Peak and contours of estimated minimum magnitude for earthquake detection

30. Minimum magnitudes required for events located at each summit to record on

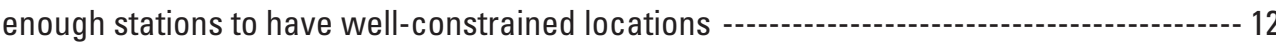

31. Contours of magnitude thresholds for "good" locations at Mount Baker ---.---.---.------- 13

32. Contours of magnitude thresholds for "good" locations at Glacier Peak -------------------- 13

33. Contours of magnitude thresholds for "good" locations at Mount Rainier---------------- 13

34. Contours of magnitude thresholds for "good" locations at Mount St. Helens --- - 13

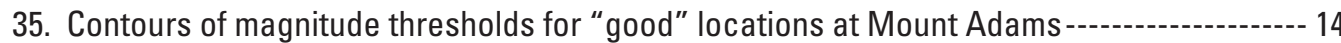

36. Contours of magnitude thresholds for "good" locations at Mount Hood -------------------- 14

37. Contours of magnitude thresholds for "good" locations at Mount Jefferson---:-------------- 14 


\section{Figures-continued}

38. Contours of magnitude thresholds for "good" locations at Three Sisters-------------------- 14

39. Contours of magnitude thresholds for "good" locations at Newberry Volcano -------------- 15

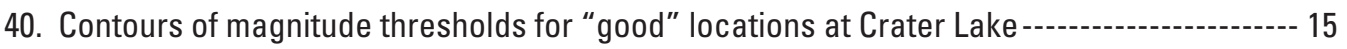

41. Contours of magnitude thresholds for "good" locations at Mount Shasta and Medicine Lake --------------------------------------------------------------- 15

42. Contours of magnitude thresholds for "good" locations at Lassen Peak --------------- 15

43. Multistation spectrogram showing a minutes-long tremor episode at Great Sitkin Volcano, Alaska----- 17

44. Contours of magnitude thresholds for "good" locations at Mount Baker network with three additional stations -------------------------------------------------- 18

45. Contours of magnitude thresholds for "good" locations at Three Sisters with four additional stations to be installed in 2004

46. Contours of magnitude thresholds for "good" locations at Three Sisters with eight additional stations, four of which are scheduled to be installed in 2004 ----------------- 20

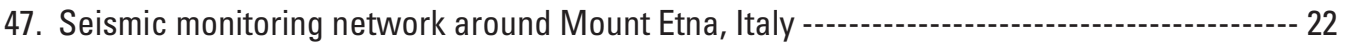




\title{
Seismic Monitoring at Cascade Volcanic Centers, 2004-Status and Recommendations
}

\author{
By Seth C. Moran
}

\section{1-Introduction}

The purpose of this report is to assess the current (May, 2004) status of seismic monitoring networks at the 13 major Cascade volcanic centers. Included in this assessment are descriptions of each network, analyses of the ability of each network to detect and to locate seismic activity, identification of specific weaknesses in each network, and a prioritized list of those networks that are most in need of additional seismic stations.

At the outset it should be recognized that no Cascade volcanic center currently has an adequate seismic network relative to modern-day networks at Usu Volcano (Japan) or Etna and Stromboli volcanoes (Italy). For a system the size of Three Sisters, for example, a modern-day, cutting-edge seismic network would ideally consist of a minimum of 10 to 12 short-period three-component seismometers (for determining particle motions, reliable $\mathrm{S}$-wave picks, moment tensor inversions, fault-plane solutions, and other important seismic parameters) and 7 to 10 broadband sensors (which, amongst other considerations, enable detection and location of very long period (VLP) and other low-frequency events, moment tensor inversions, and, because of their wide dynamic range, on-scale recording of large-amplitude events). Such a dense, multi component seismic network would give the ability to, for example, detect in near-real-time earthquake migrations over a distance of $\sim 0.5 \mathrm{~km}$ or less, locate tremor sources, determine the nature of a seismic source (that is, pure shear, implosive, explosive), provide on-scale recordings of very small and very large-amplitude seismic signals, and detect localized changes in seismic stress tensor orientations caused by movement of magma bodies.

However, given that programmatic resources are currently limited, installation of such networks at this time is unrealistic. Instead, this report focuses on identifying what additional stations are needed to guarantee that anomalous seismicity associated with volcanic unrest will be detected in a timely manner and, in the case of magnitude $\geq 1$ earthquakes, reliably located.

\section{2-Seismic monitoring at Cascade volcanic centers-the big picture}

Seismic activity at Cascade volcanic centers is monitored by a composite network of seismic stations (fig. 1) operated by several groups. These groups include the Pacific Northwest Seismograph Network (PNSN), operated by the University of Washington in cooperation with several other entities (such as the University of Oregon), and the Northern California Seismic Network (NCSN), jointly operated by the U.S. Geological Survey (USGS) Earthquake Hazards Team in Menlo Park and the University of California Berkeley. Both groups receive funding from the USGS Volcano Hazards Program, the USGS Earthquake Hazards Program through the National Earthquake Hazards Reduction Program (NEHRP) and Advanced National Seismic System (ANSS) programs, the National Oceanic and Atmospheric Administration (NOAA) through the Cooperative Remote sEnsing Science and Technology (CREST) program for tsunami mitigation, and other sources. Waveform data is shared in real time between these networks and other groups (including the Cascades Volcano Observatory (CVO)) via the USGS Earthworm data acquisition system (Bittenbinder and others, 1994). The PNSN also uses this system to receive data from several Canadian stations operated by the Pacific Geoscience Centre in Sydney, British Columbia.

The PNSN/NCSN combined network has a total of 44 stations within $20 \mathrm{~km}$ of individual stratovolcanoes, and 66 within $40 \mathrm{~km}$ (figs. 1, 2). The vast majority of these are shortperiod, vertical-component stations that use analog telemetry. This number also includes four broadband seismometers (one each near Rainier, Hood, Newberry, and Shasta; most are CREST-funded sites), two short-period three-component seismometers (Three Sisters, Lassen Peak), and five ANSS- and CREST-funded strong-motion accelerometers (near Mount Baker, Mount Rainier, Mount Hood, Three Sisters, and Newberry Volcano; three of these are co located with broadband instruments). CVO currently receives real-time data from 50 of these stations.

\section{3-Seismic networks by volcano}

Figures 3 through 14 show seismic stations within $\sim 40$ $\mathrm{km}$ of the 13 individual Cascade volcanic centers. Maps are drawn to similar, but not identical, scales, with the exception of Shasta/ Medicine Lake. Yellow triangles represent shortperiod vertical-component instruments, cyan represent shortperiod three-component instruments, red represent broadband (BB) seismometers, and green represent strong-motion (SMO) accelerometers. White circles correspond to locations of shallow $(<10 \mathrm{~km})$ earthquakes occurring between 2000-2003. Signals from short-period instruments are telemetered in real time 
to analysis centers for the respective networks using analog radios.

\section{4-Assessment of the ability of net- works to detect anomalous seismicity}

Detection of anomalous seismicity in all its possible forms (volcano-tectonic (VT) earthquakes, hybrid or "mixed- frequency" events, long-period (LP) events, VLP events, tremor, and surface events (such as rockfalls, avalanches, and explosions)) is one of the chief roles of a volcano seismic network. Detection occurs either with automated computer-based programs or the human eye. Automated detection of earthquakes and surface events works well for VTs, hybrids, impulsive LP events, and large-amplitude surface events, as long as a sufficiently dense network is in place. It does not work well for non impulsive and (or) low-amplitude events, particularly

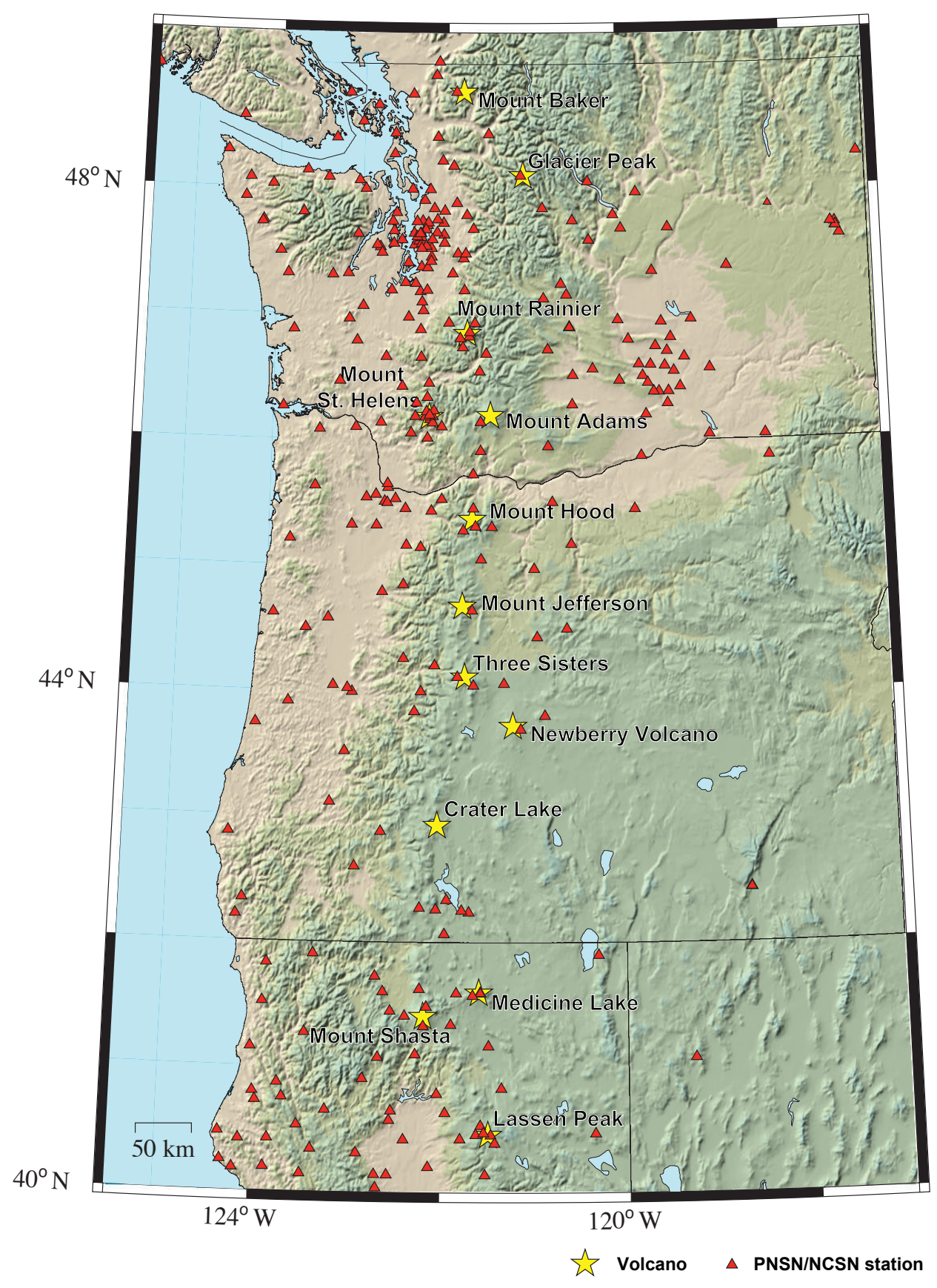

Figure 1. Shaded relief map showing locations of all seismic stations (red triangles) operating in the Pacific Northwest as of November, 2003. Locations of the 13 major Cascade volcanic centers are indicated by yellow stars. 
tremor. Detection of these signals is more often dependent upon human analysts, even with relatively dense networks in place.

The easiest way to measure a network's ability to detect seismicity is to look at earthquake detection, as this is (mostly) done by computer algorithms and is thus relatively straightforward to quantify. There are two ways to characterize the detection capabilities of a network. One is the detection threshold magnitude, which is the magnitude of the smallest earthquake that can be automatically detected (but not necessarily located). The other is the magnitude of completeness, which is the magnitude of the smallest event that will, in theory, always be detected and located. Both can be assessed by looking at earthquake catalogs, providing there are sufficient numbers of earthquakes. This is done in sections 4.1.1 to 4.1.2. However, most volcanoes in Oregon have insufficient seismicity, so section 4.1.3 presents theoretical detection thresholds for each volcano.

\section{1- Earthquake Catalogs - what has been detected?}

\subsection{1—Detection threshold}

The detection threshold can be estimated by looking at the smallest-magnitude earthquake to be located by a seismic network. However, this may underestimate the true detection threshold slightly, as earthquakes can be detected without being located (as would happen if a detected earthquake only appeared on two stations). It also is a poor estimate for regions with sparse seismicity

Figure 15 shows the smallest magnitude earthquake located within $20 \mathrm{~km}$ of each of the major Cascade volcanic centers between 1990 and 2003. Note that this is a poor measure for most Oregon volcanic centers, specifically Mount Jefferson (1 located event), Three Sisters (6), Newberry Volcano $(0)$, and Crater Lake (4). On the other hand, the $M=0.0$ value for Lassen Peak is a true detection threshold that I determined by first estimating coda-duration magnitudes for VT events in a February 2004 swarm, then examining NCSN trigger log files (courtesy of D. Oppenheimer, 2004) to determine which events did and did not trigger the NCSN acquisition system.

\subsection{2-Magnitude of completeness}

The magnitude of completeness (Mc) is determined through a b-value analysis of an earthquake catalog. This analysis uses the Gutenberg-Richter relationship between earthquake magnitude and the number of events with magnitude $M$ :

$$
\log N(M)=a-b^{*} M
$$

$N(M)$ is the number of events with magnitude $M, b$ is the slope, and $a$ the x-axis intercept. In general the relationship between $M$ and $N(M)$ is log-linear, and the "b-value" is the slope of this linear relationship. However, small earthquakes are less reliably detected and located than larger events, as their signals can be more easily masked by natural noise

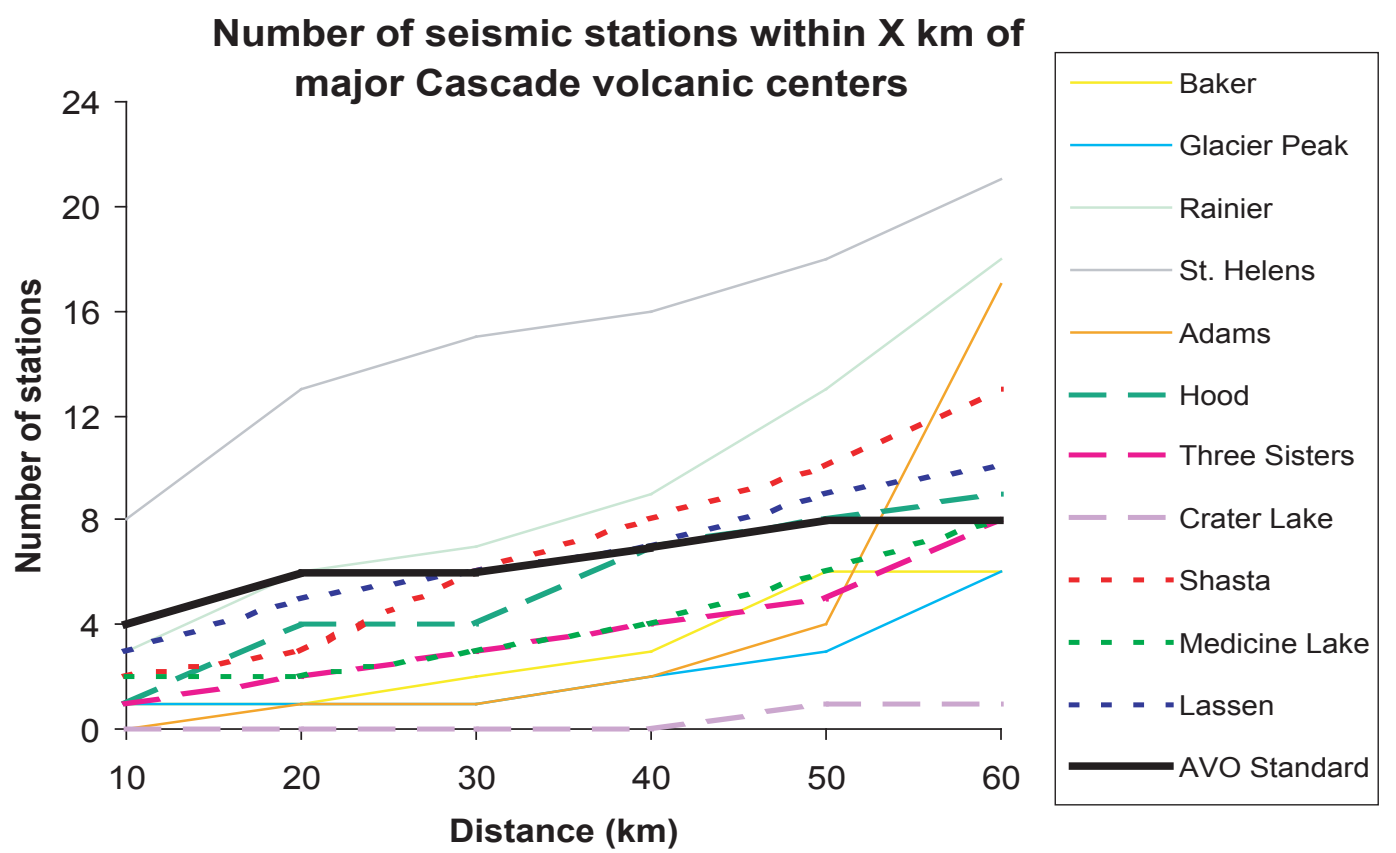

Figure 2. Plot showing number of stations within $X \mathrm{~km}$ of 11 Cascade volcanoes (Newberry and Jefferson, which are equivalent to Adams out to $50 \mathrm{~km}$, were omitted for clarity). "AVO Standard" reflects typical network installed by the Alaska Volcano Observatory (AVO). 


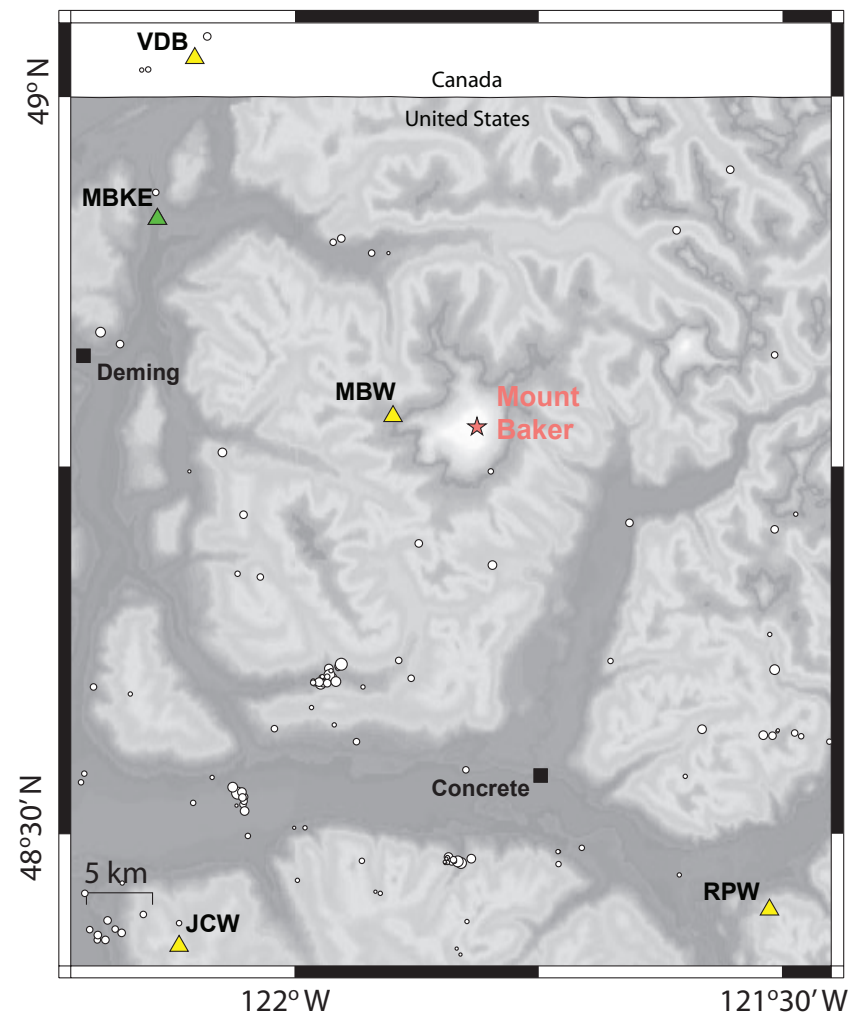

Figure 3. Mount Baker seismic network. For this and all other mapview plots ( figs. 4-14, 18-29, 31-42, and 44-45), yellow triangles represent short-period vertical component seismometers, cyan triangles represent short-period three component seismometers, green triangles represent strong-motion accelerometers, red triangles represent broadband seismometers, and white circles represent earthquakes with circle size scaled to magnitude.

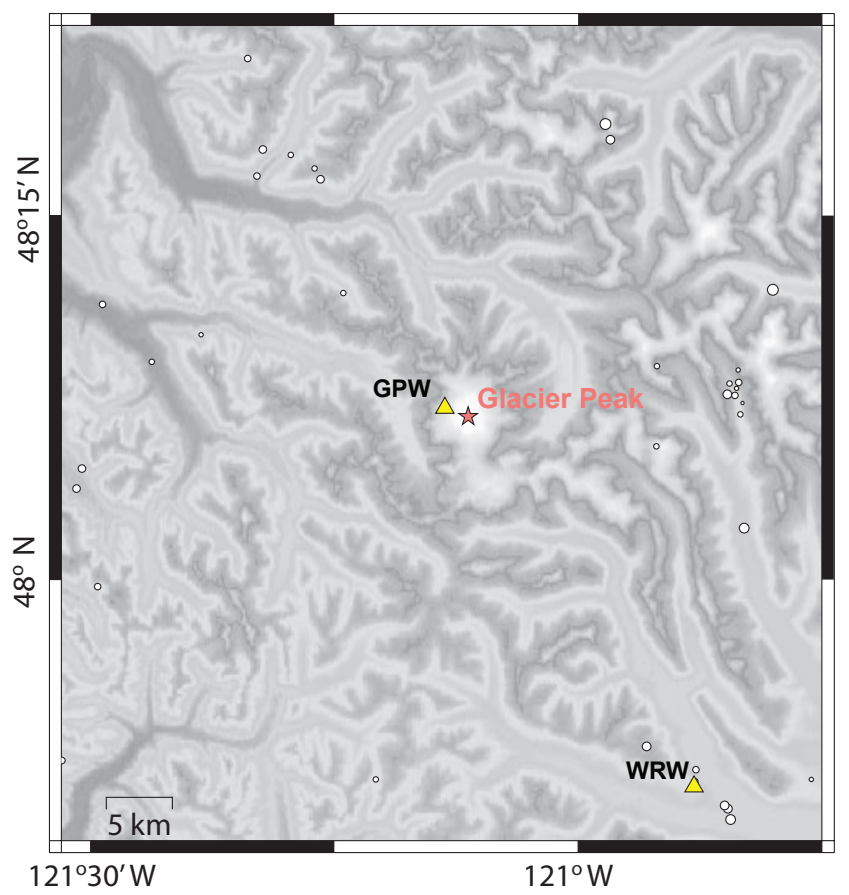

Figure 4. Glacier Peak seismic network. See figure 3 for symbol explanation.

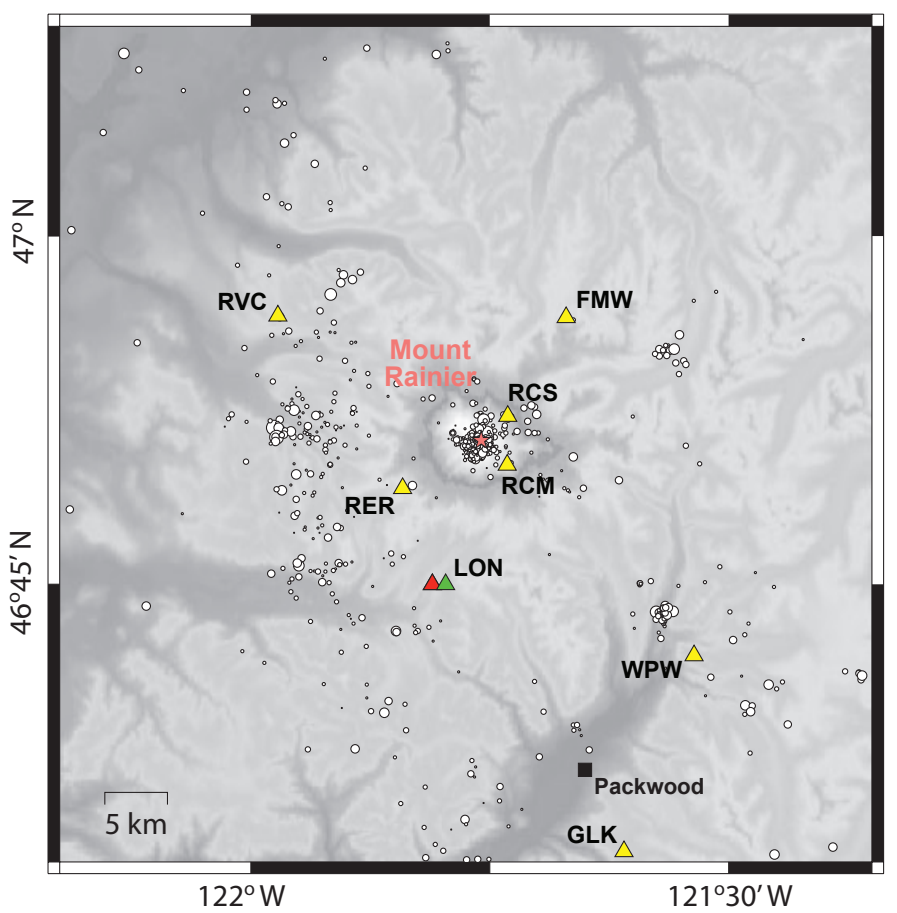

Figure 5. Mount Rainier seismic network. Note that one station (LON) has both a broadband and a strong-motion sensor. See figure 3 for symbol explanation.

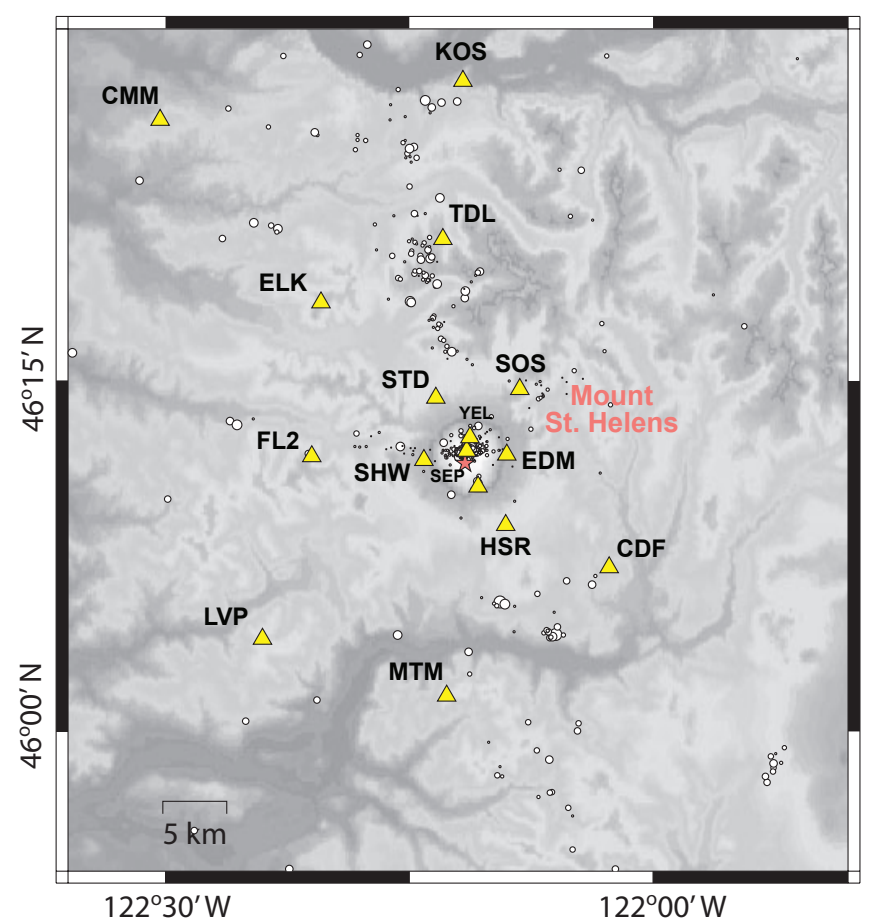

Figure 6. Mount St. Helens seismic network. See figure 3 for symbol explanation. 


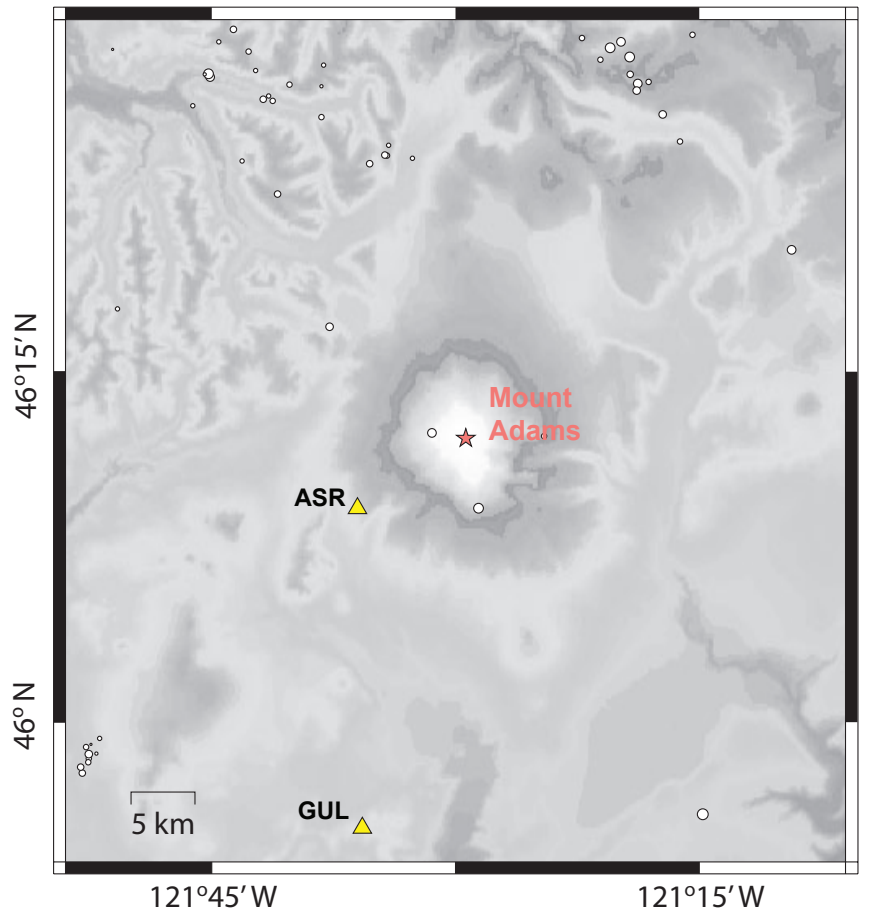

Figure 7. Mount Adams seismic network. See figure 3 for symbol explanation.

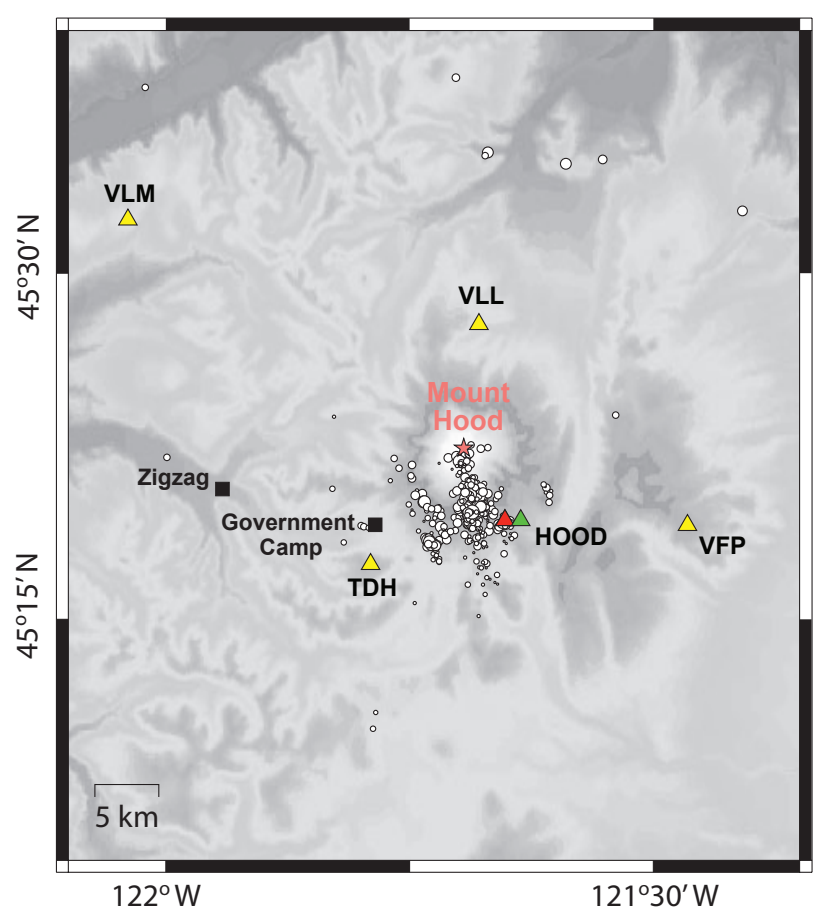

Figure 8. Mount Hood seismic network. Note that one station (HOOD) has both a broadband and a strong-motion sensor. See figure 3 for symbol explanation.

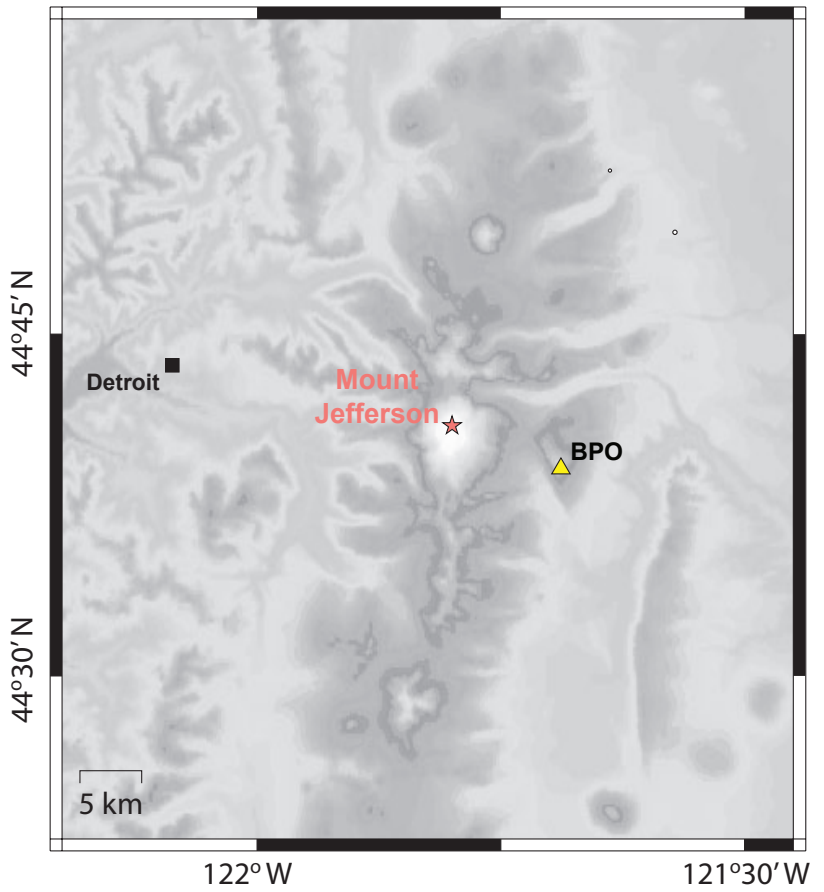

Figure 9. Mount Jefferson seismic network. See figure 3 for symbol explanation.

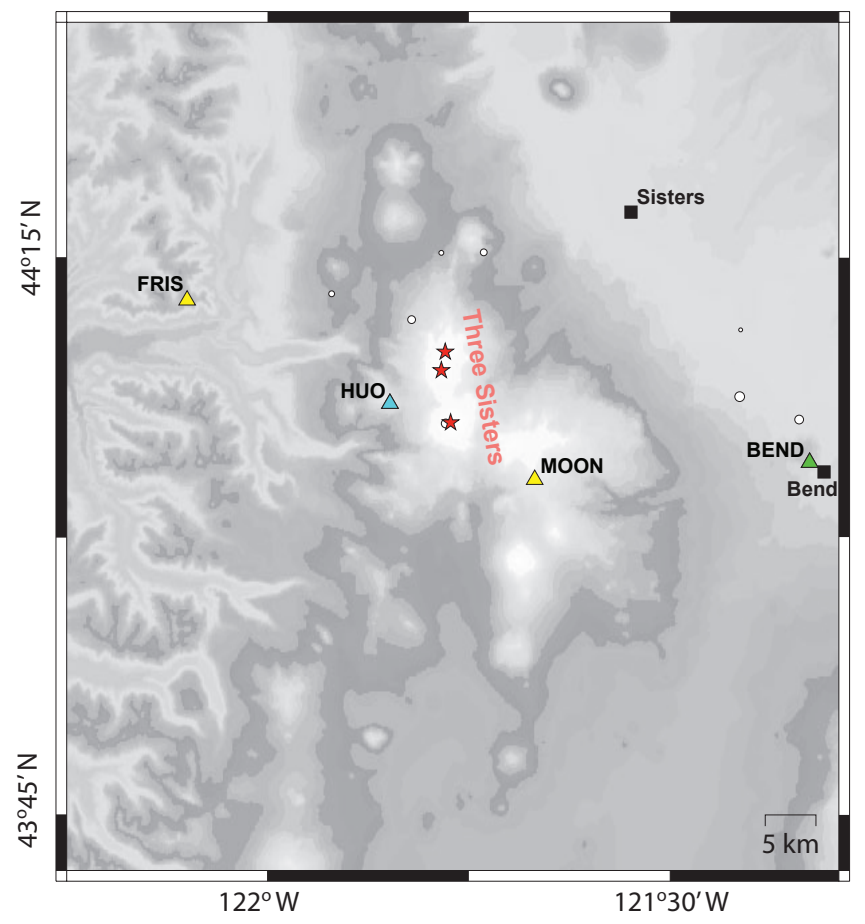

Figure 10. Three Sisters seismic network. See figure 3 for symbol explanation. 


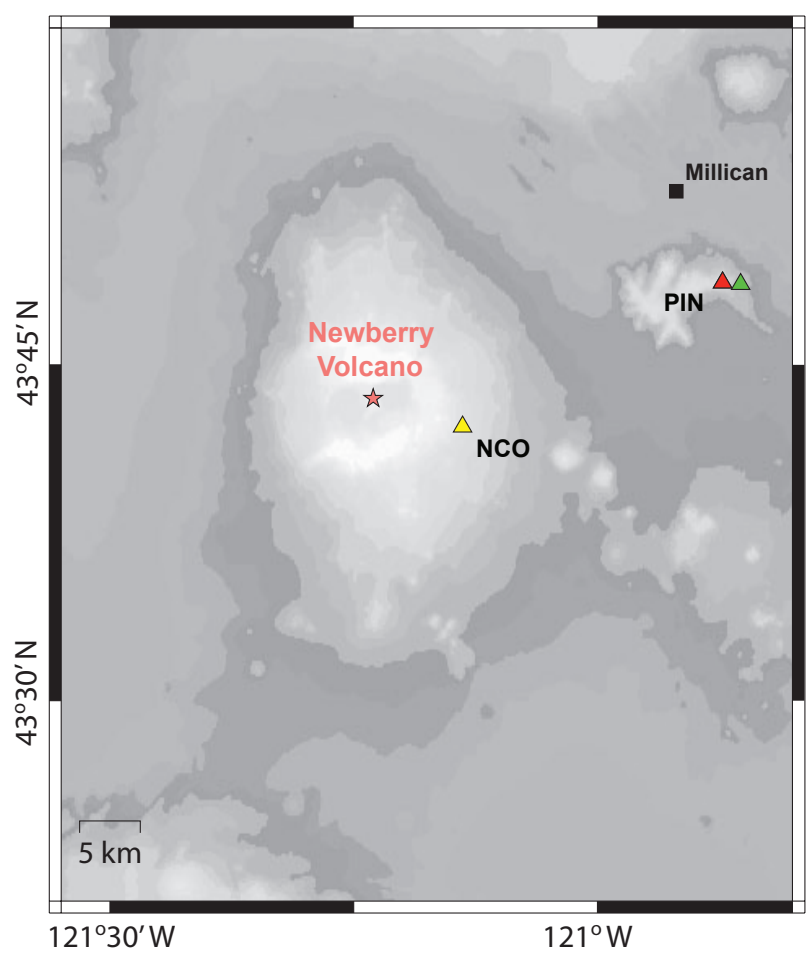

Figure 11. Newberry Volcano seismic network. Note that one station (PIN) has both a broadband and a strong-motion sensor. See figure 3 for symbol explanation.

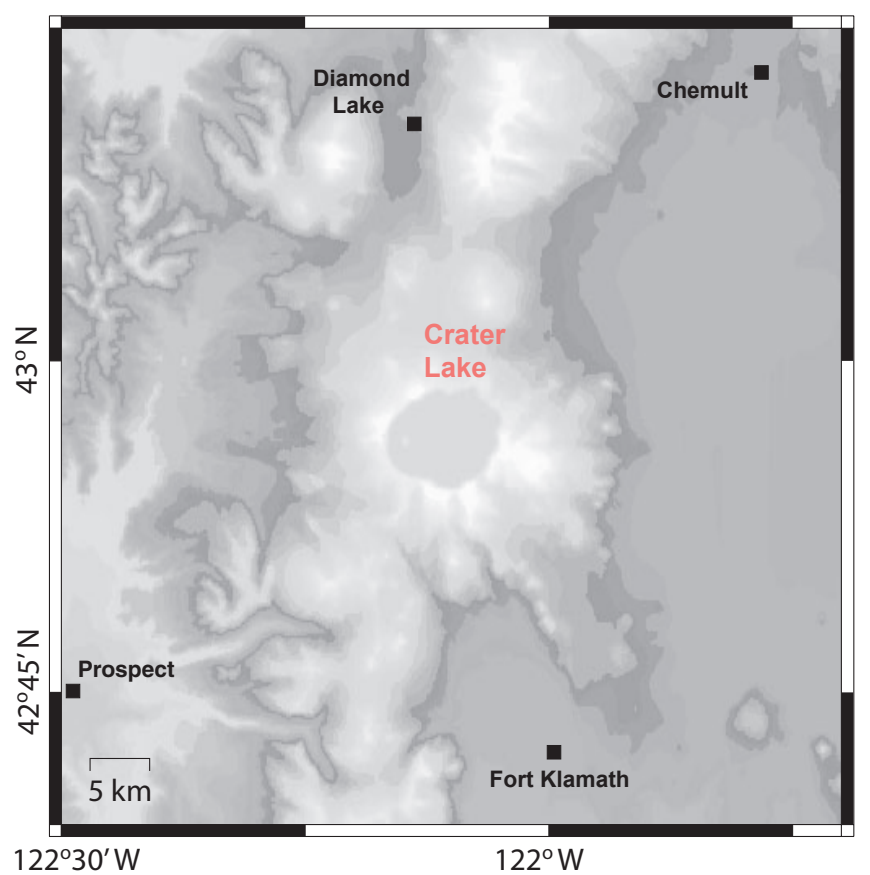

Figure 12. Crater Lake seismic network. See figure 3 for symbol explanation.

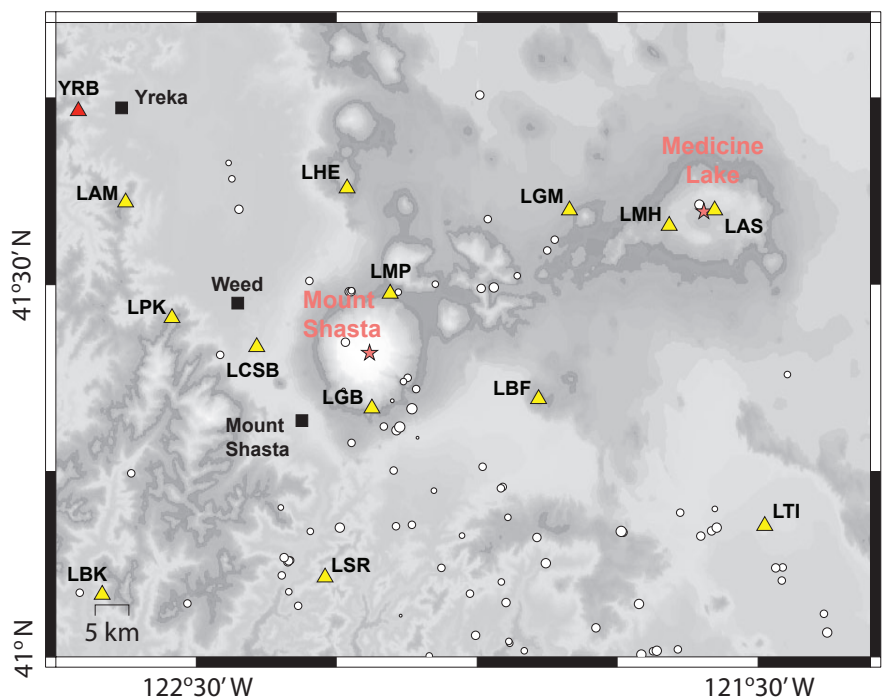

Figure 13. Mount Shasta and Medicine Lake seismic networks. Signals are telemetered via satellite (Nanometrics VSAT) to U.S. Geological Survey offices in Menlo Park, Calif. See figure 3 for symbol explanation.

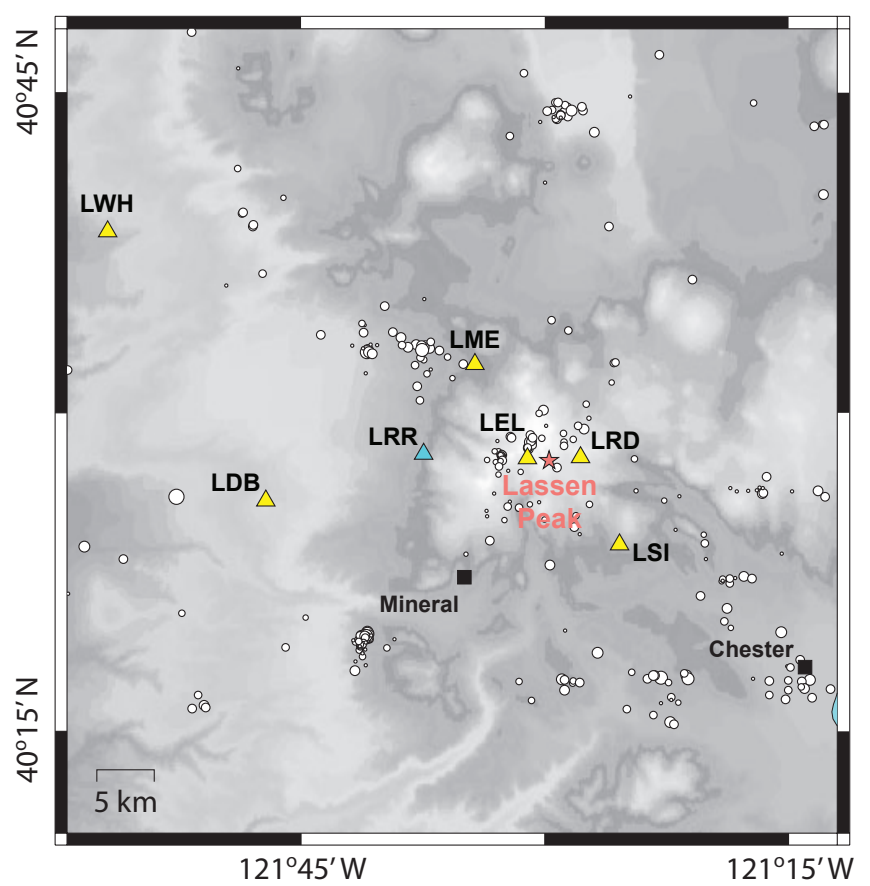

Figure 14. Lassen Peak seismic network. See figure 3 for symbol explanation. 
sources, such as wind. Additionally, their small amplitudes make their detection and location more vulnerable to station outages, as they show up on far fewer stations than large events. In all catalogs there is a critical magnitude Mc below which the Gutenberg-Richter relationship breaks down. This is widely taken to represent the magnitude below which earthquakes are sometimes missed; alternatively, it is the magnitude above which earthquakes are always detected.

Figure 16 shows $\mathrm{Mc}$ for each volcano network. Note that there were insufficient numbers of earthquakes for b-value analyses at most volcanic centers except Mount Rainier, Mount St. Helens, Mount Hood, Mount Shasta, and Mount Lassen. This demonstrates that a theoretical approach is needed to assess detection and location capabilities at most Cascade volcanic centers.

\subsection{3-Theoretical detection threshold}

When there are too few earthquakes to empirically assess detection capabilities of seismic networks, the next best approach is to generate theoretical estimates of detection thresholds. Because earthquake detection is usually done automatically, computer programs can be written to mimic these automated detection systems.

Most automated event-detection systems (such as the Earthworm system used by the PNSN and NCSN) employ a subnet-trigger algorithm. All stations are continuously monitored for significant short-term increases in seismic amplitude. If enough stations within a defined subnet experience significant increases at roughly the same time, then the subnet "trig- gers" and waveform data is saved for subsequent analysis by a human (if the event is big enough, an automated location may also be produced). Thus event detection is dependent upon the number of seismic stations in each subnet, their proximity to a volcano, their sensitivity (including site and path effects), and the number of stations required for a subnet to trigger.

For simplicity, all stations and sites are assumed to have identical sensitivities. The theoretical detection threshold is then computed by (1) calculating the distance from each latitude/longitude grid point to the Xth closest station, where X is the number of stations required for a given subnet to trigger (so if a subnet has a 4-station trigger requirement, then compute the distance to the $4^{\text {th }}$ closest station); (2) Using a modified version of the Richter magnitude scale to convert distance and minimum amplitude required to trigger a given station into a magnitude $\left(\mathrm{M}_{\mathrm{L}}\right)$. The relationship (modified to best reflect minimum magnitude earthquake distributions at Mounts St. Helens and Rainier) is:

$$
\mathrm{M}_{\mathrm{L}}=\log (\text { Amplitude })+1.7 * \log (\text { distance_to_Xth_station })-2.38
$$

Amplitude here isn't truly a peak-peak amplitude; instead it is the minimum amplitude above background required to trigger a single station. In most cases this number was $a$ priori chosen to be 2 . At Three Sisters and Lassen Peak the Amplitude factor was empirically determined to be 3 and 3.5, respectively, using recent swarms to gauge the actual detection threshold (as was described above for Lassen Peak).

The resulting magnitude is an estimate of the smallest event at each latitude/longitude grid point that would trigger a given volcano subnet. Note that this estimate neglects variations in equation (1) with increasing depth, assumes that all

\section{Smallest earthquake located within $20 \mathrm{~km}$ of volcano}

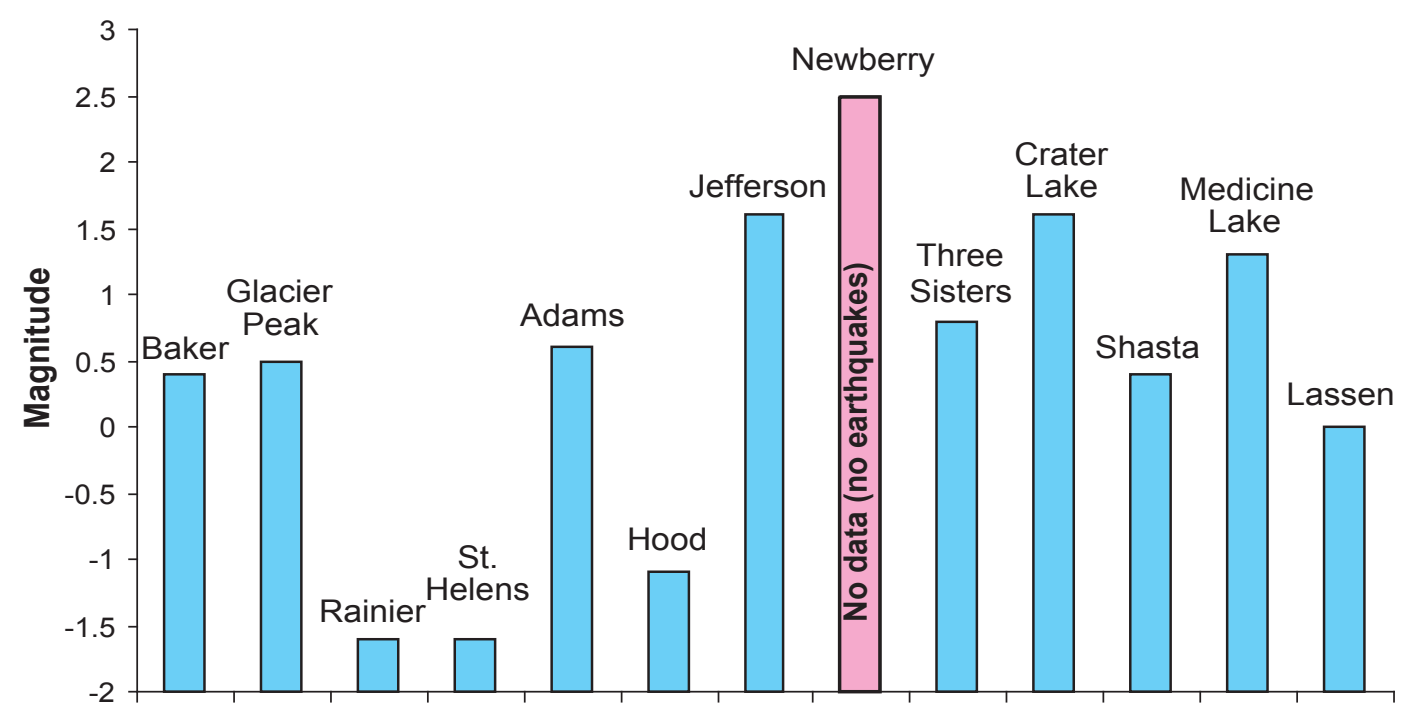

Figure 15. Smallest magnitude earthquake within $20 \mathrm{~km}$ of volcano between 1990-2003. This is an estimate of the magnitude below which earthquakes will never be detected. 
sites have identical sensors and site responses, assumes that all sites are functioning, and assumes that background noise is constant. In other words, these are only estimates of detection thresholds based on ideal conditions and a simplified view of seismometers and the Earth. Thus the detection threshold estimates have an unknown error, which I estimate to be $+/-0.2-$ 0.3 magnitude units.

Figure 17 shows detection thresholds at the latitude and longitude of the centroid of each volcanic center, and figures 18-29 show detection threshold contours for each network.

\subsection{4-Theoretical "good" location threshold}

In the absence of seismicity, it is even more difficult to estimate the magnitude of completeness (see section 4.1.2 and fig. 16). One way of addressing this is to use the same methodology described in section 4.1.3 to determine the minimum magnitude required for an event to appear on enough stations to allow for the determination of a "good", or well-constrained, location. Two network-geometry-dependent criteria are important for a "good" location; maximum azimuthal gap (or "maximum gap") between stations relative to the epicenter, and distance to the nearest station. For reasonable accuracy in latitude and longitude determinations, the maximum gap should be $<<180^{\circ}$. Any gap larger than $180^{\circ}$ can cause artificial epicentral patterns, such as dike-like linear patterns of epicenters trending away from a network. For accurate depth determinations, at least one station needs to be within one "skin depth" of an earthquake's epicenter (i.e., the distance to the nearest station needs to be $\leq$ earthquake depth).

Figures 30 through 42 show the estimated minimum magnitudes required for an event to have a well-constrained location, defined here as having a maximum azimuthal gap between stations of $\angle=135^{\circ}$ (one of the PNSN criteria for a quality "B" solution). As with the estimated detection thresholds in figures 17 through 29 , it should be remembered that the magnitude contours are only estimates that probably have an error of a few tenths of a magnitude unit. It should also be noted that these contours were not computed using a closest station criterion (10 km or less for a PNSN quality "B" location), as this is solely dependent upon location and thus holds for all magnitudes. Volcanoes without a station within $10 \mathrm{~km}$ of the summit (red star in the map-view figures) are shown in pink in figure 30 .

\section{2- Important seismic-monitoring criteria other than earthquake detection and location}

Detection and location of VT and impulsive LP events can be achieved by standard vertical-component short-period instruments. If there are sufficient numbers of these instruments, first-motion focal mechanisms can also be determined. However, other types of sensors are needed to adequately record and detect nonstandard seismic sources. Three-component instruments are necessary for (1) accurately picking S-wave arrivals, which are particularly important for depth

\section{Magnitude of completeness (Mc) for eqs w/in $20 \mathrm{~km}$}

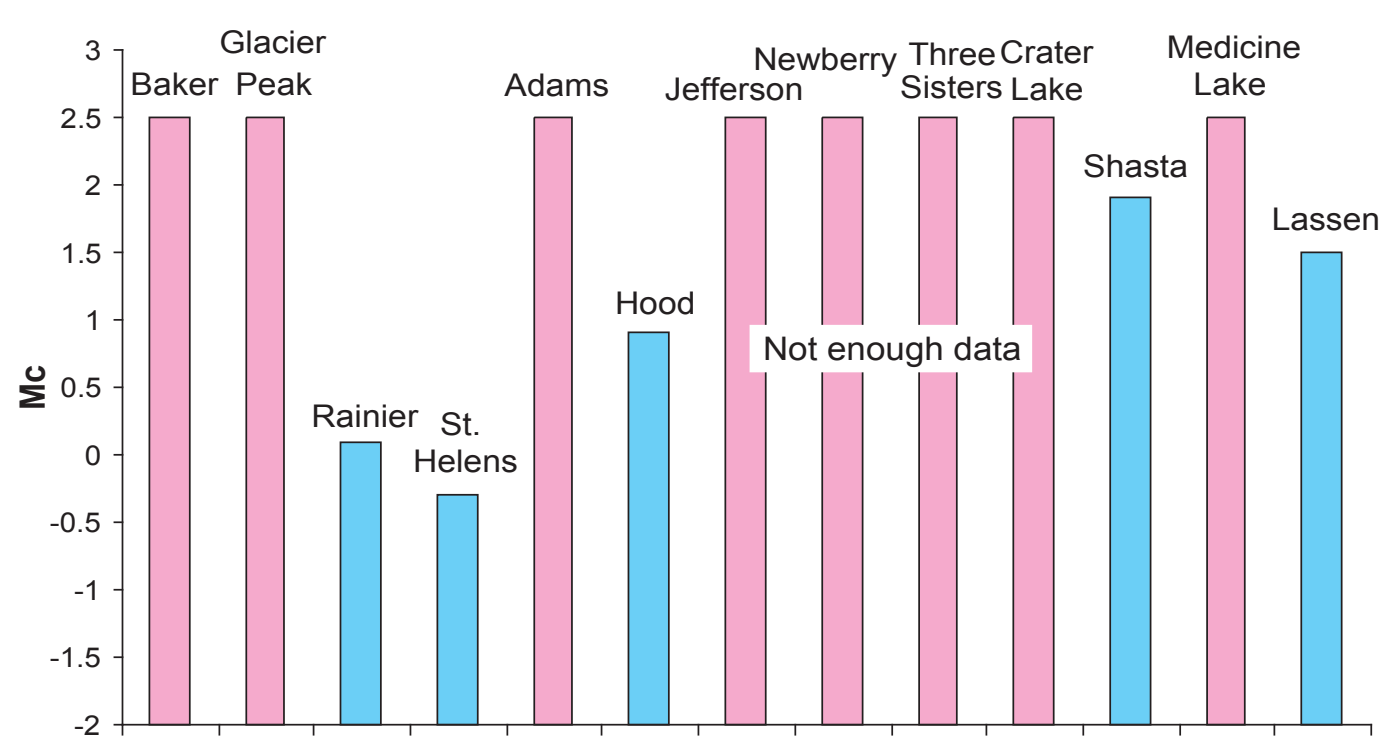

Figure 16. Magnitude of completeness (Mc) for earthquakes within $20 \mathrm{~km}$ of volcano between 1990-2003. Earthquakes with magnitudes $\geq$ Mc will, in theory, always be detected. Centers with too few earthquakes to determine b-values are colored pink. 


\section{Theoretical earthquake detection threshold}

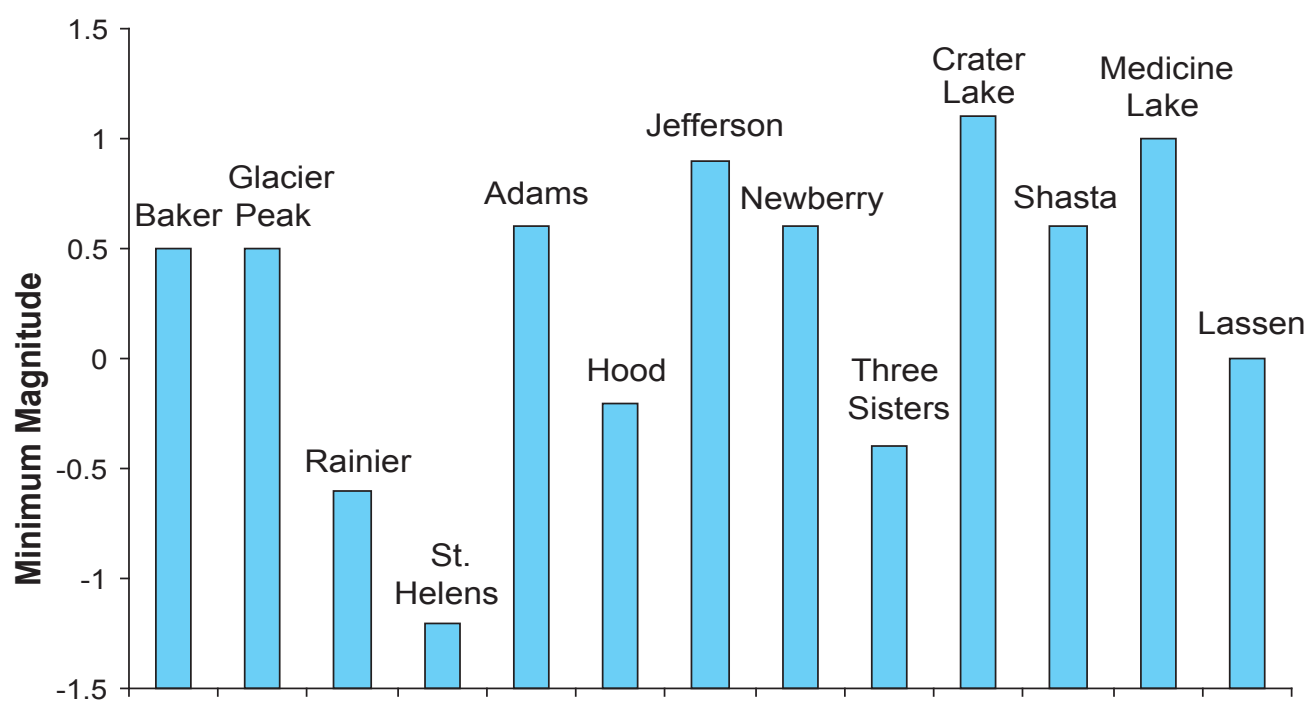

Figure 17. Estimates of detection thresholds at the summit (red star) of each volcano. This estimate represents the magnitude below which an event will never be detected.

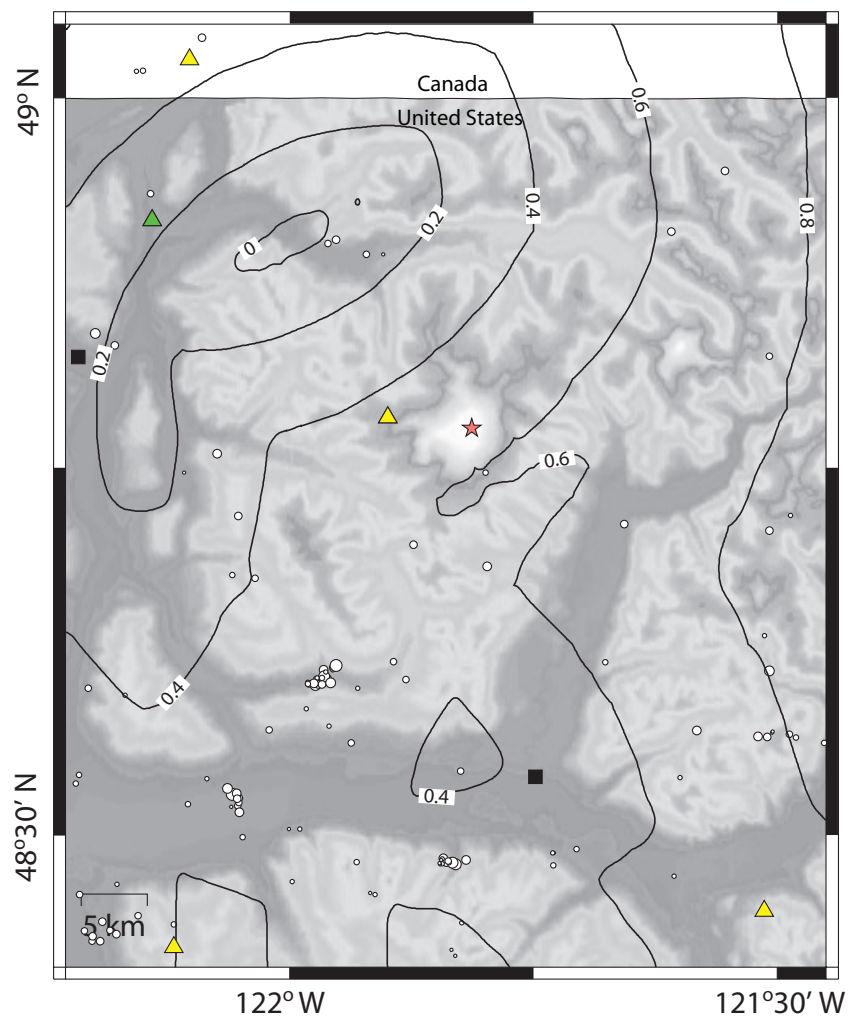

Figure 18. Mount Baker and contours of estimated minimum magnitude for earthquake detection.

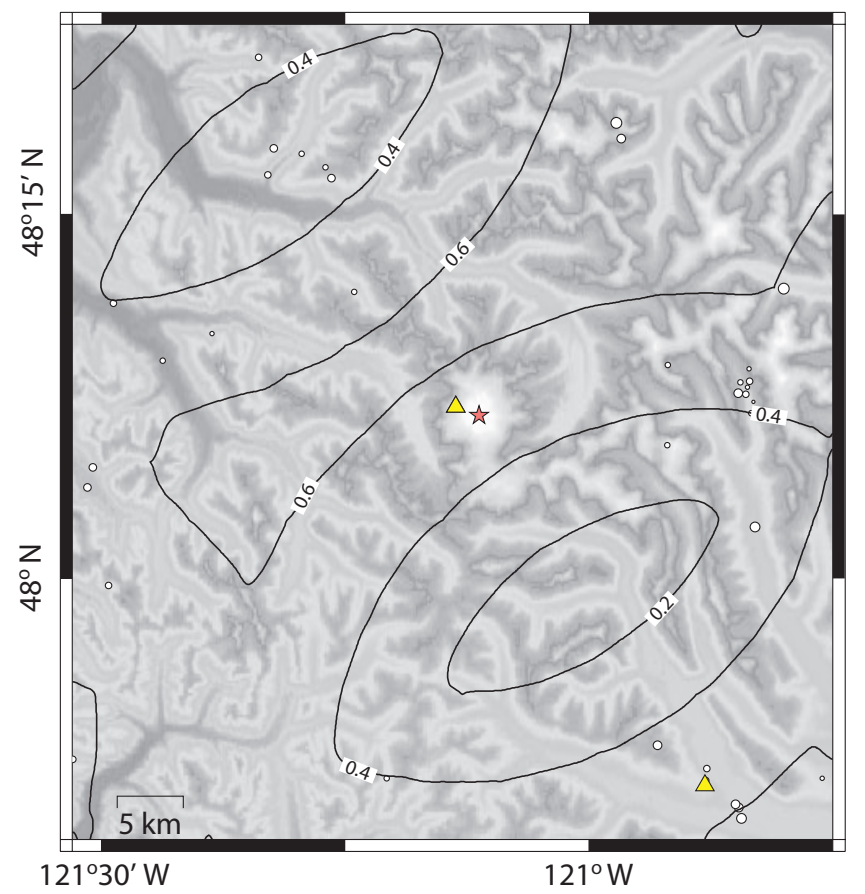

Figure 19. Glacier Peak and contours of estimated minimum magnitude for earthquake detection. 


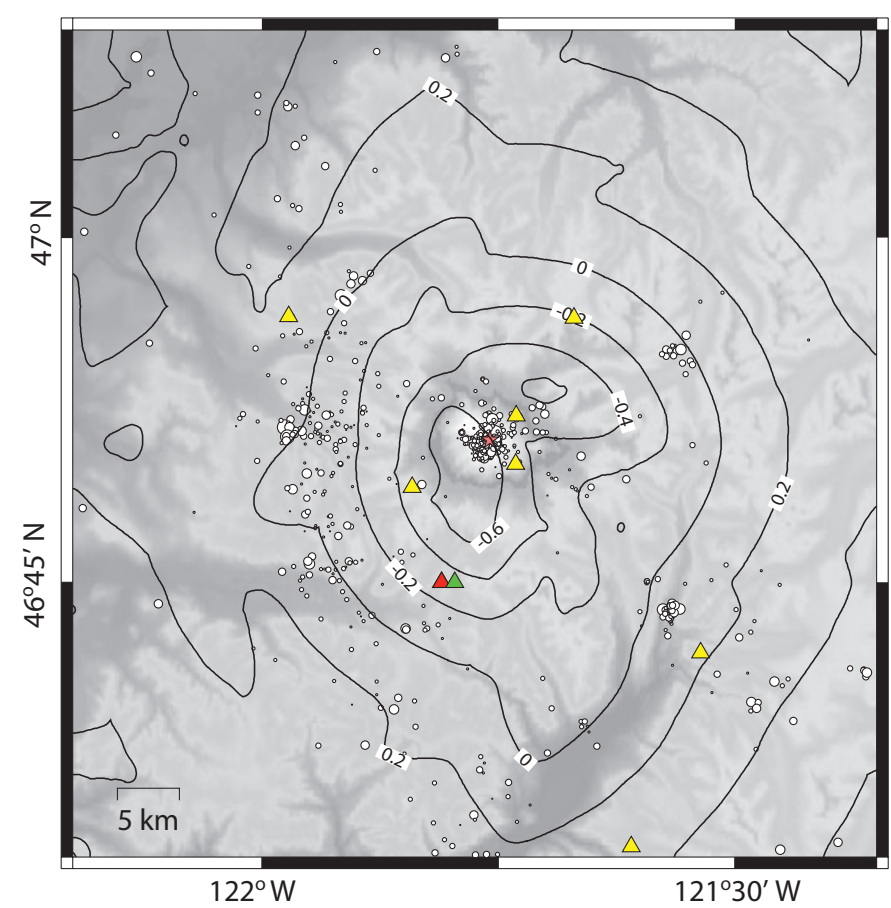

Figure 20. Mount Rainier and contours of estimated minimum magnitude for earthquake detection.

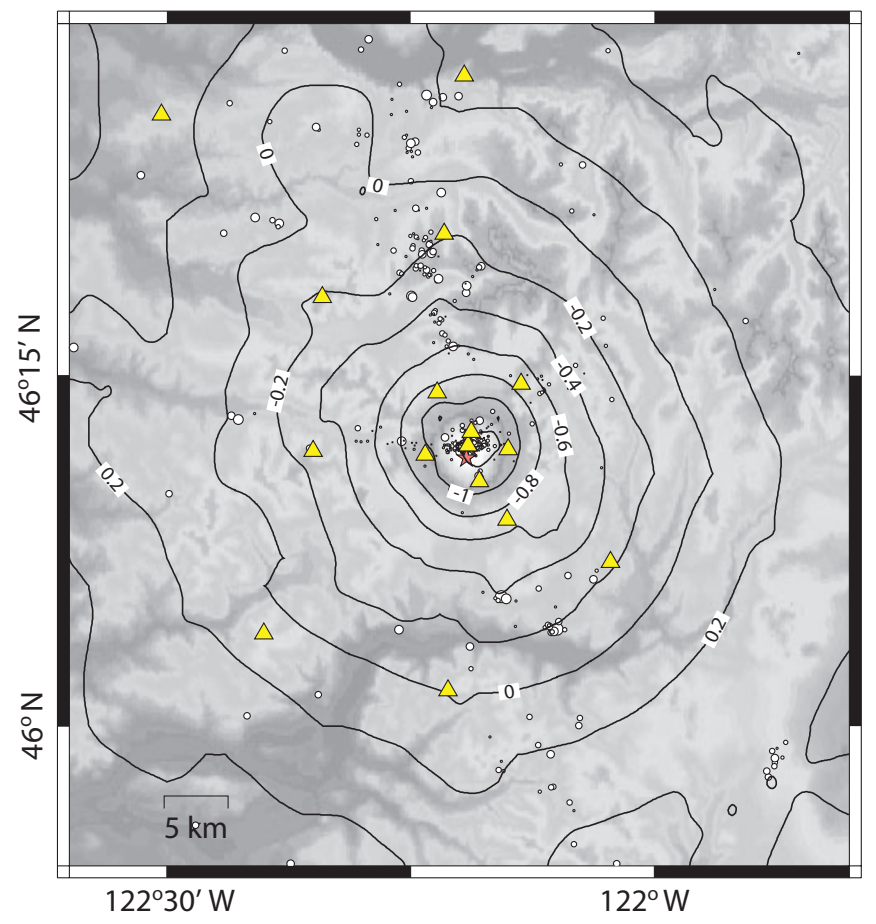

Figure 21. Mount St. Helens and contours of estimated minimum magnitude for earthquake detection.

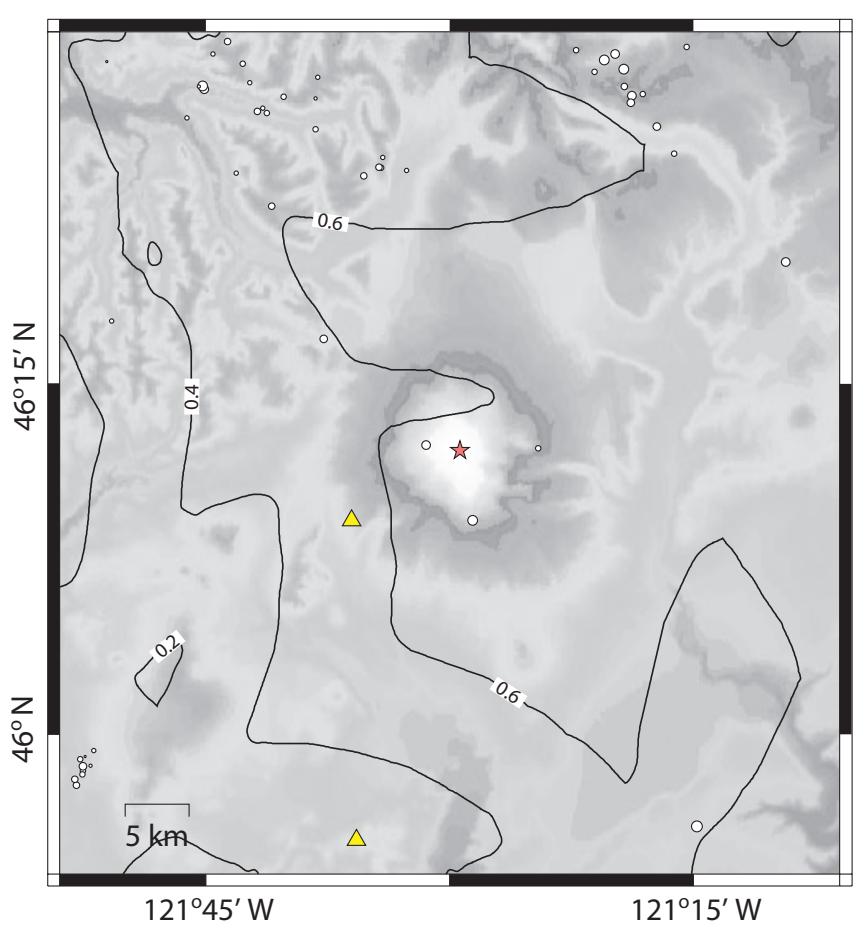

Figure 22. Mount Adams and contours of estimated minimum magnitude for earthquake detection.

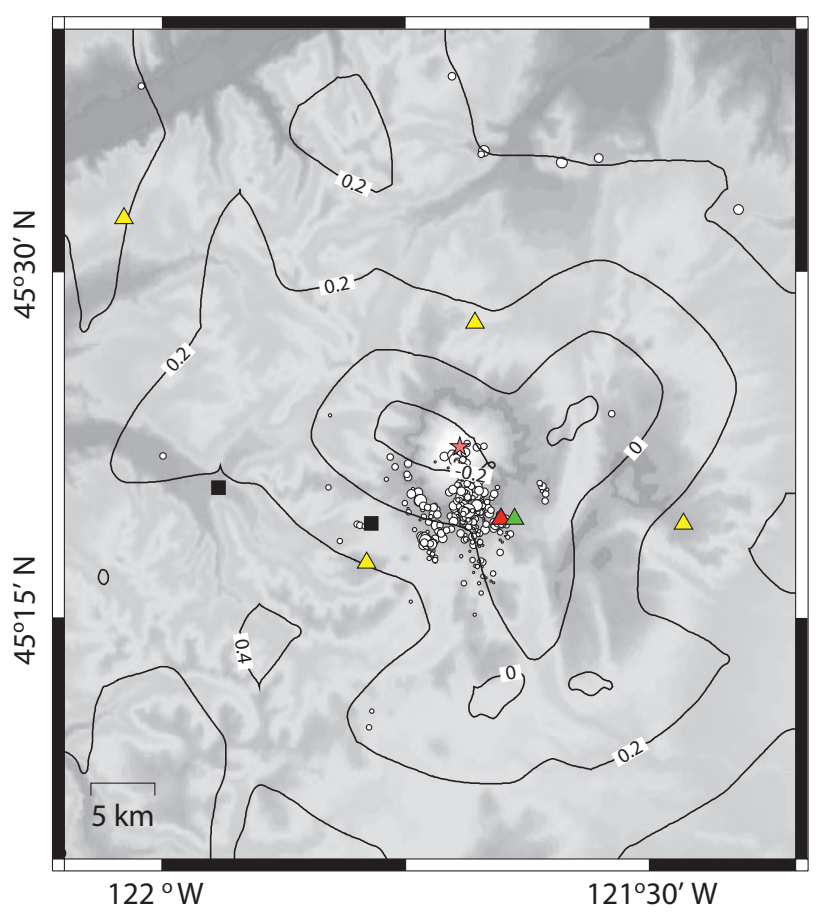

Figure 23. Mount Hood and contours of estimated minimum magnitude for earthquake detection. 


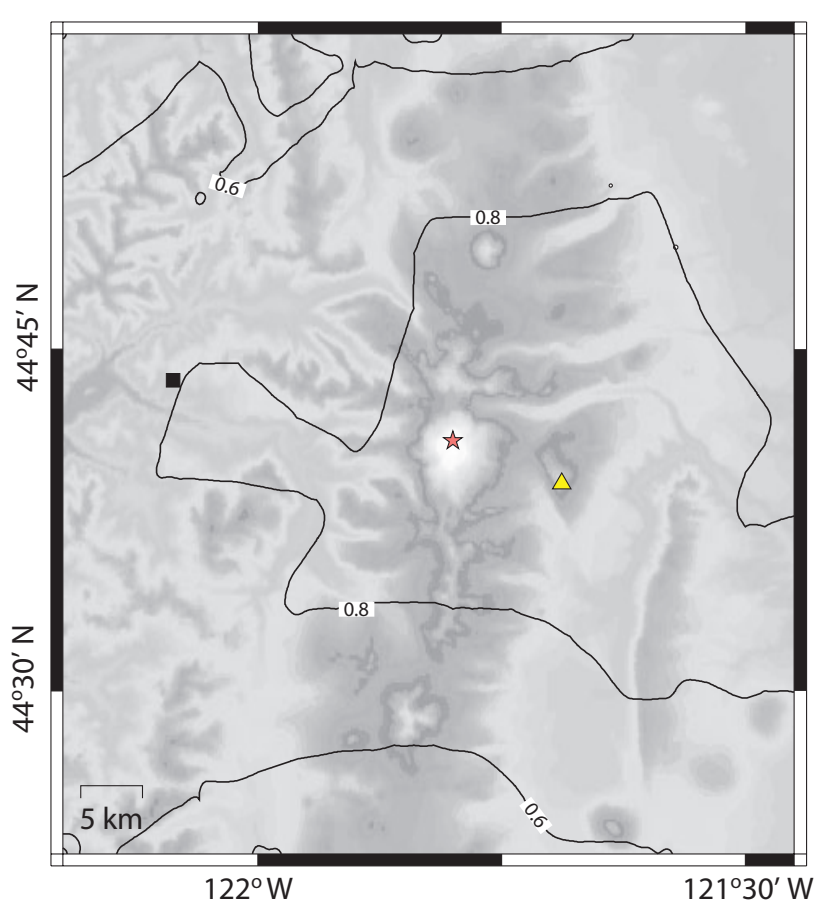

Figure 24. Mount Jefferson and contours of estimated minimum magnitude for earthquake detection.

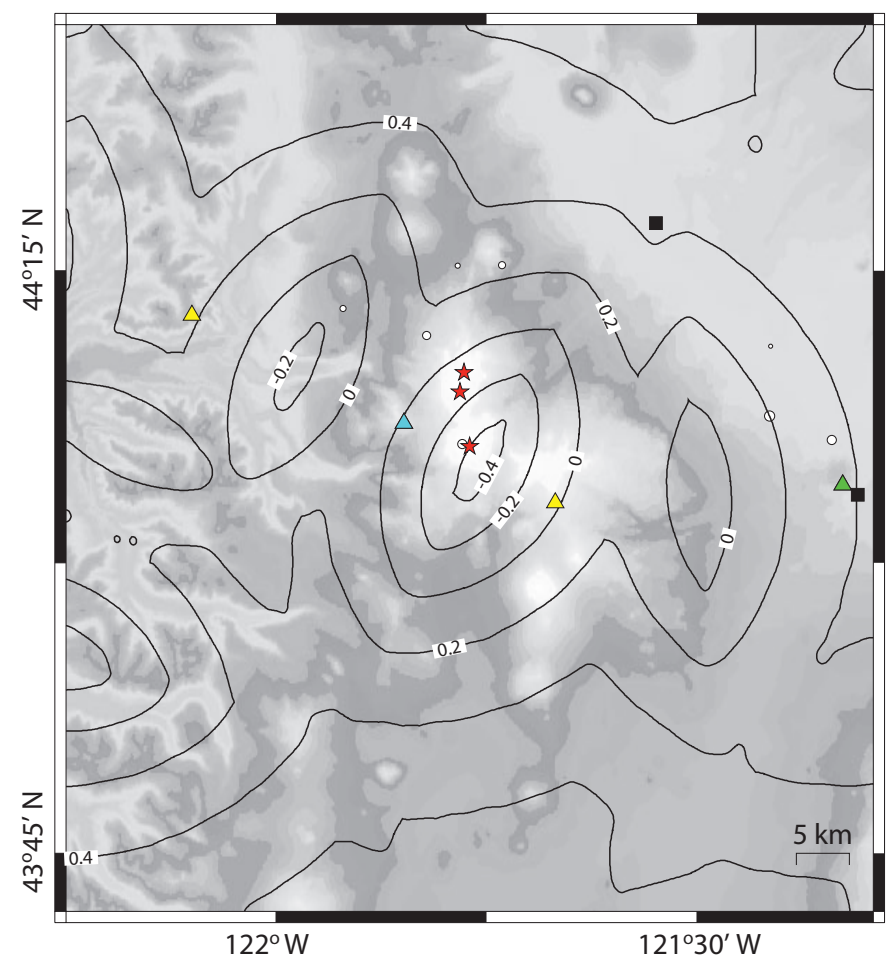

Figure 25. Three Sisters and contours of estimated minimum magnitude for earthquake detection.

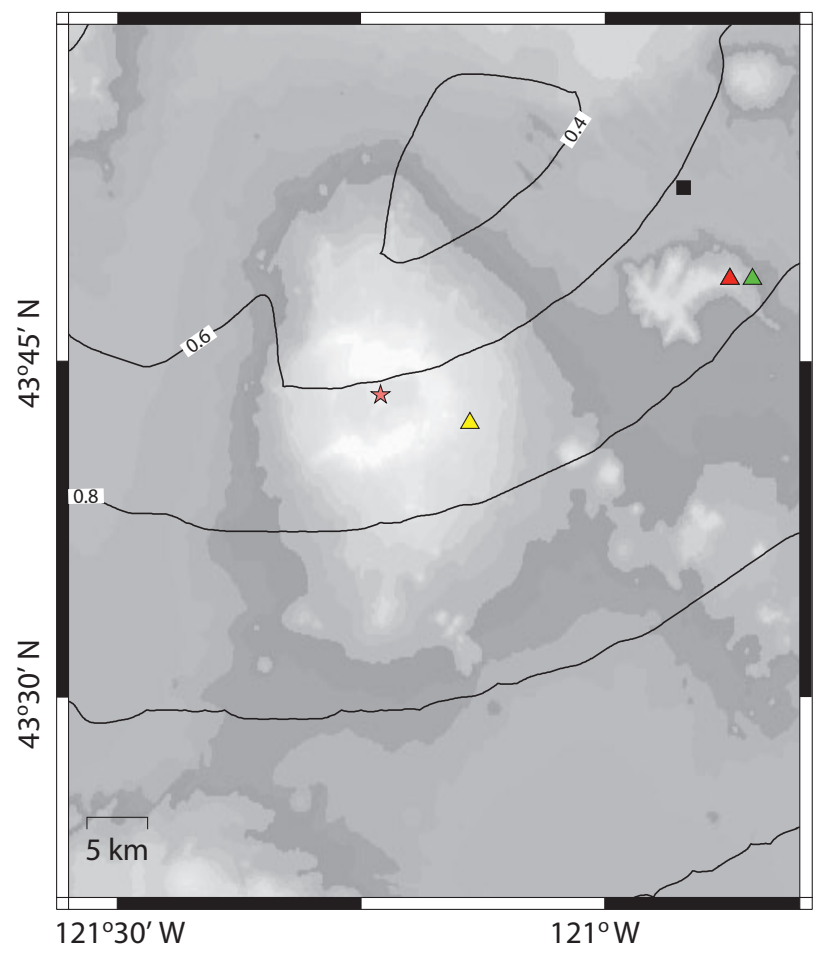

Figure 26. Newberry Volcano and contours of estimated minimum magnitude for earthquake detection.

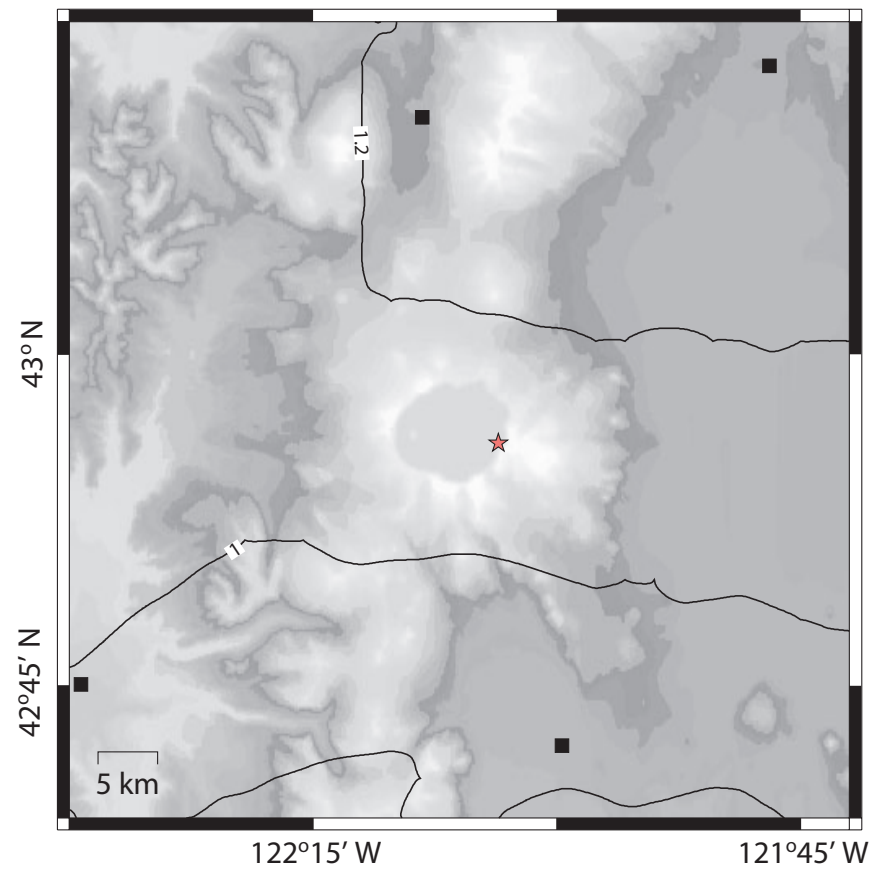

Figure 27. Crater Lake and contours of estimated minimum magnitude for earthquake detection. 


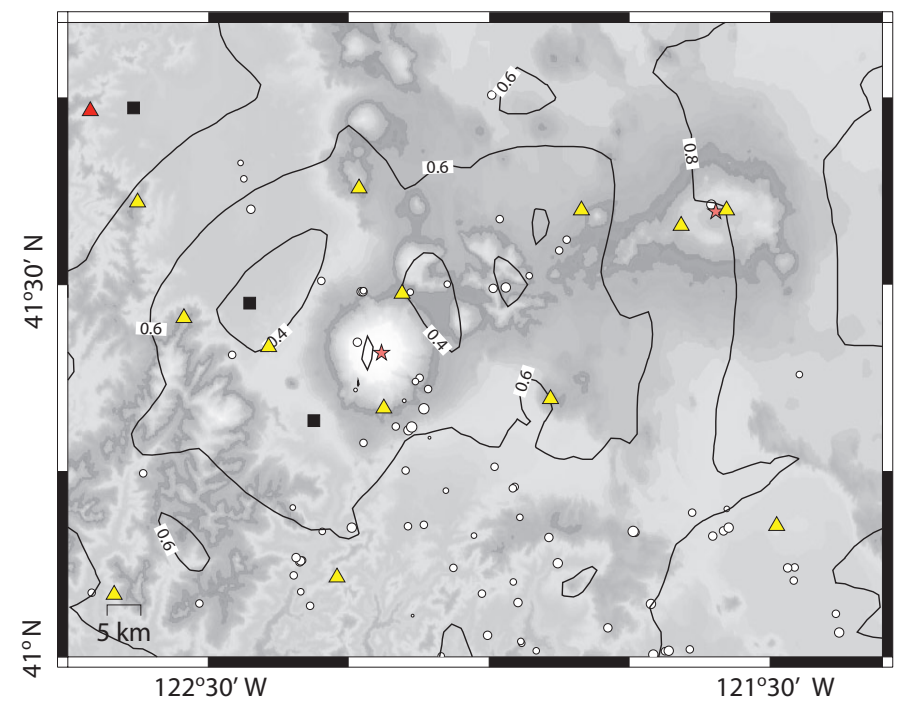

Figure 28. Mount Shasta and Medicine Lake contours of estimated minimum magnitude for earthquake detection.

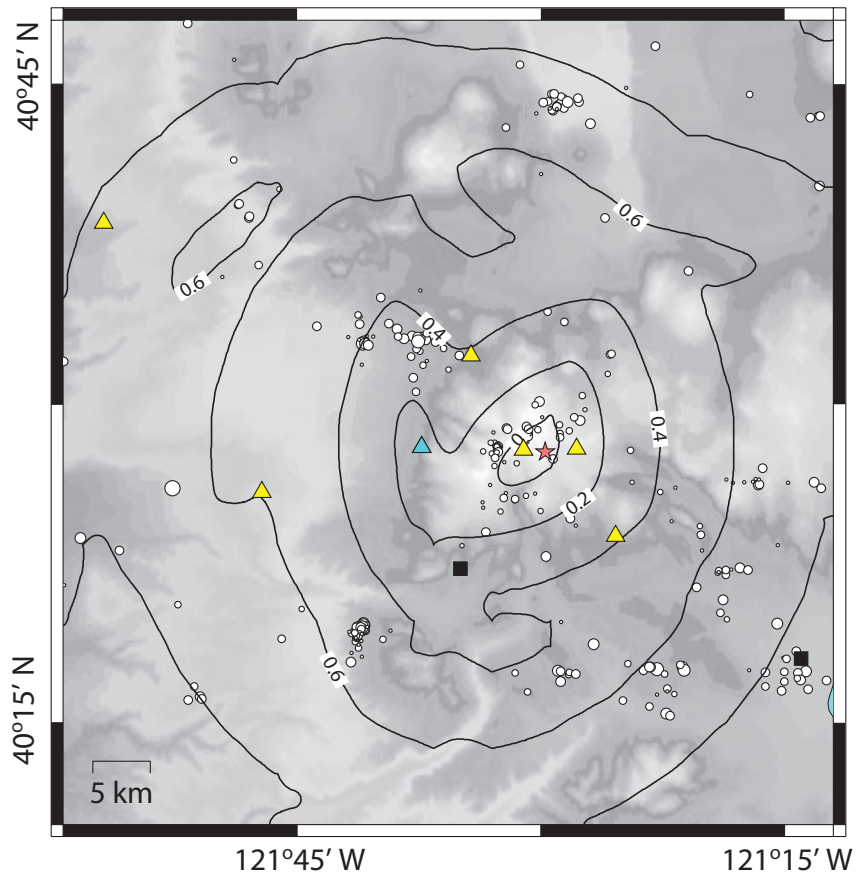

Figure 29. Lassen Peak and contours of estimated minimum magnitude for earthquake detection.

\section{Theoretical "good" location threshold}

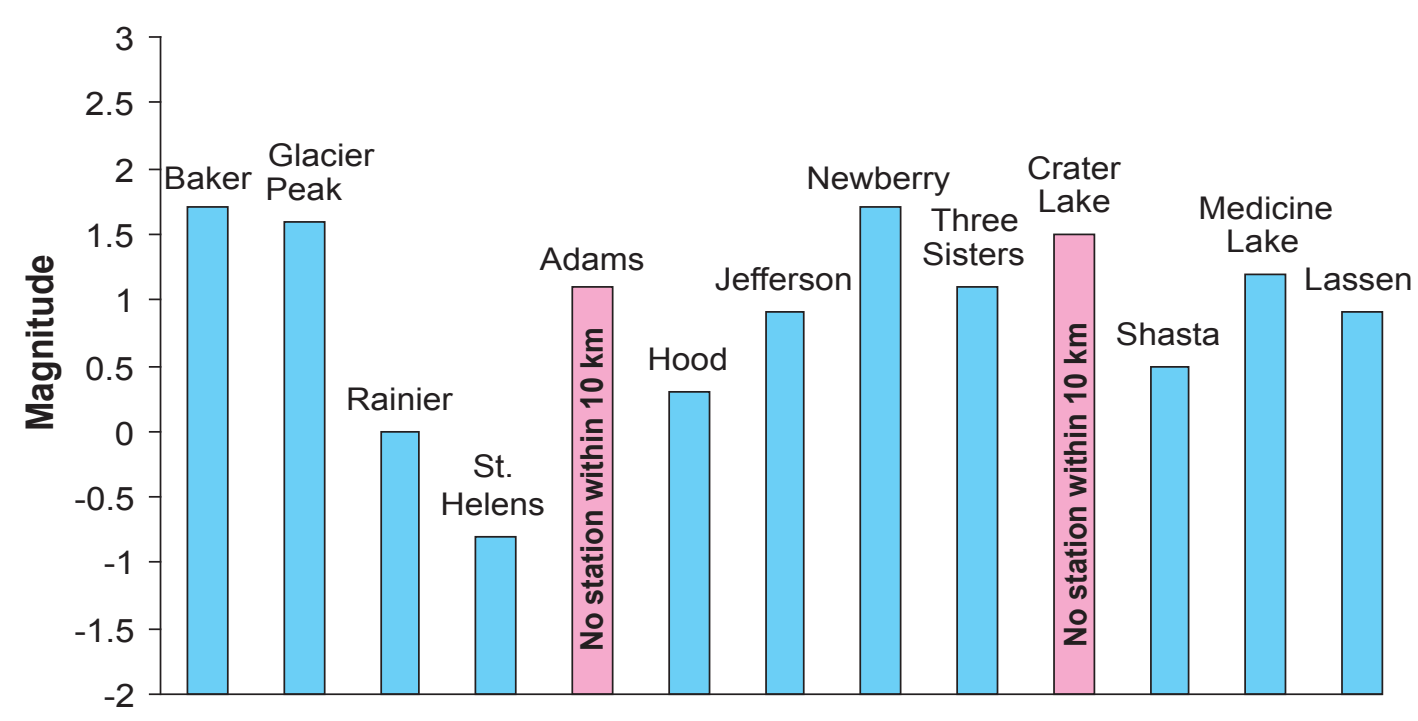

Figure 30. Minimum magnitudes required for events located at each summit to record on enough stations to have well-constrained locations (maximum gap $<135^{\circ}$ ). Mount Adams and Crater Lake are colored pink because they have no station within $10 \mathrm{~km}$, so events beneath each summit will have poorly constrained depths. 


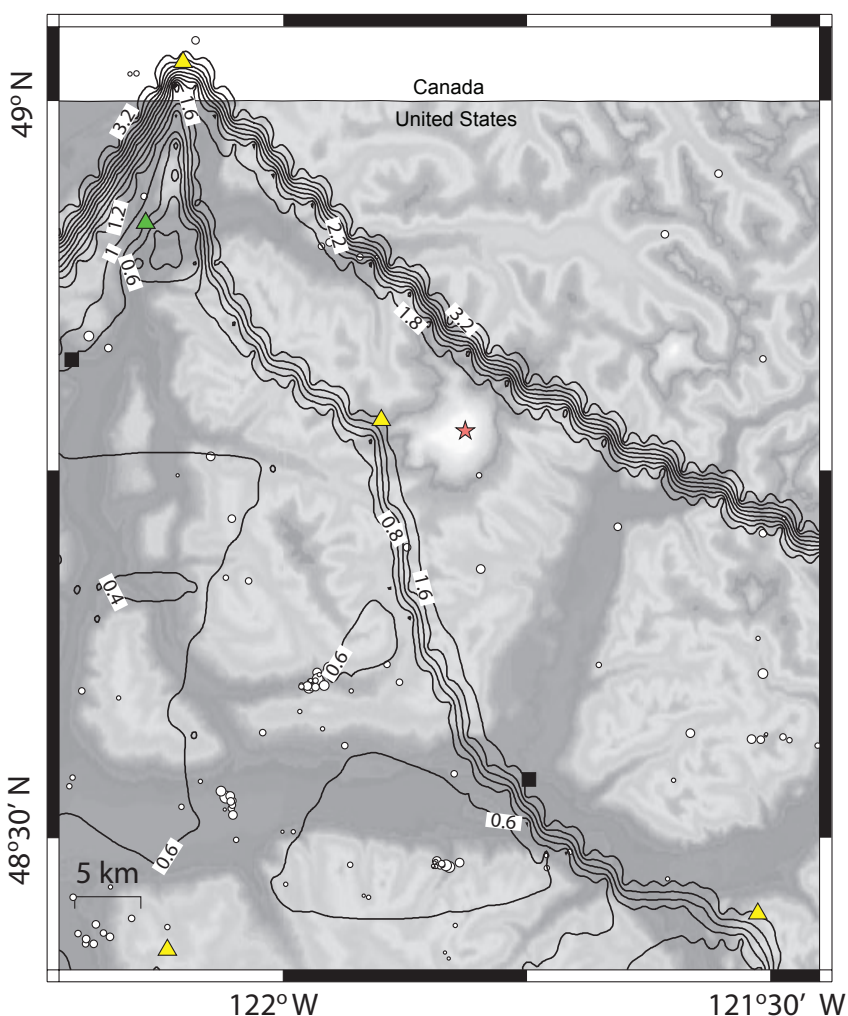

Figure 31. Contours of magnitude thresholds for "good" locations at Mount Baker. "Wobbles" in contours shown here and in figures 32 through 42 are artifacts due to tight contour spacing and an inexact contouring program.

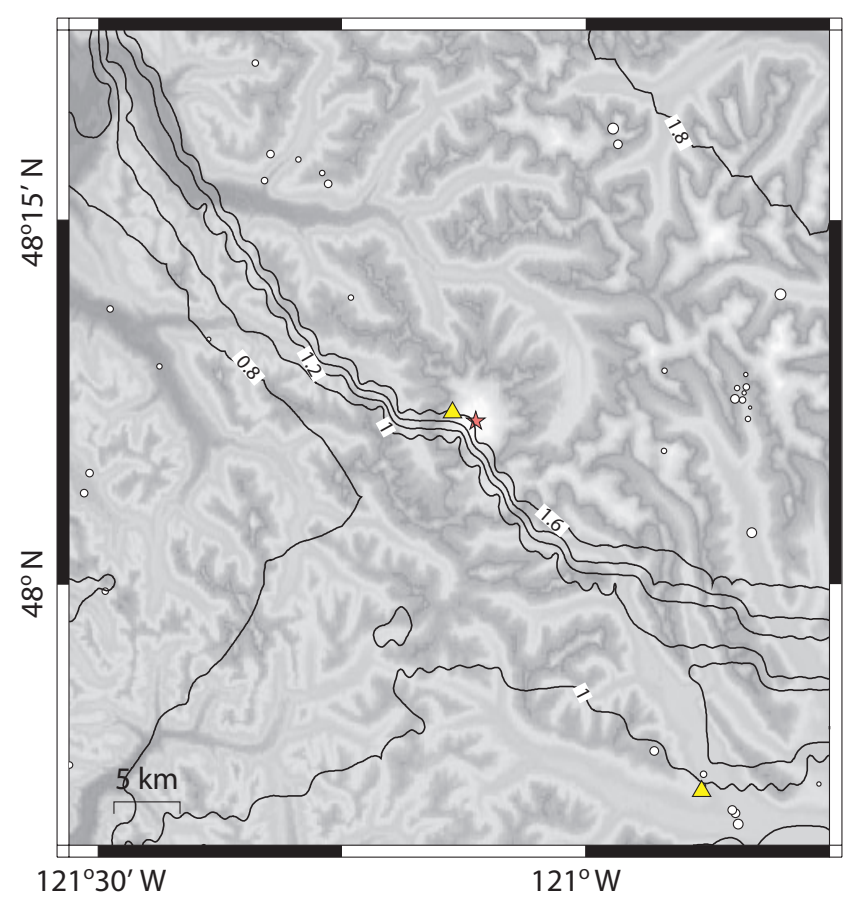

Figure 32. Contours of magnitude thresholds for "good" locations at Glacier Peak.

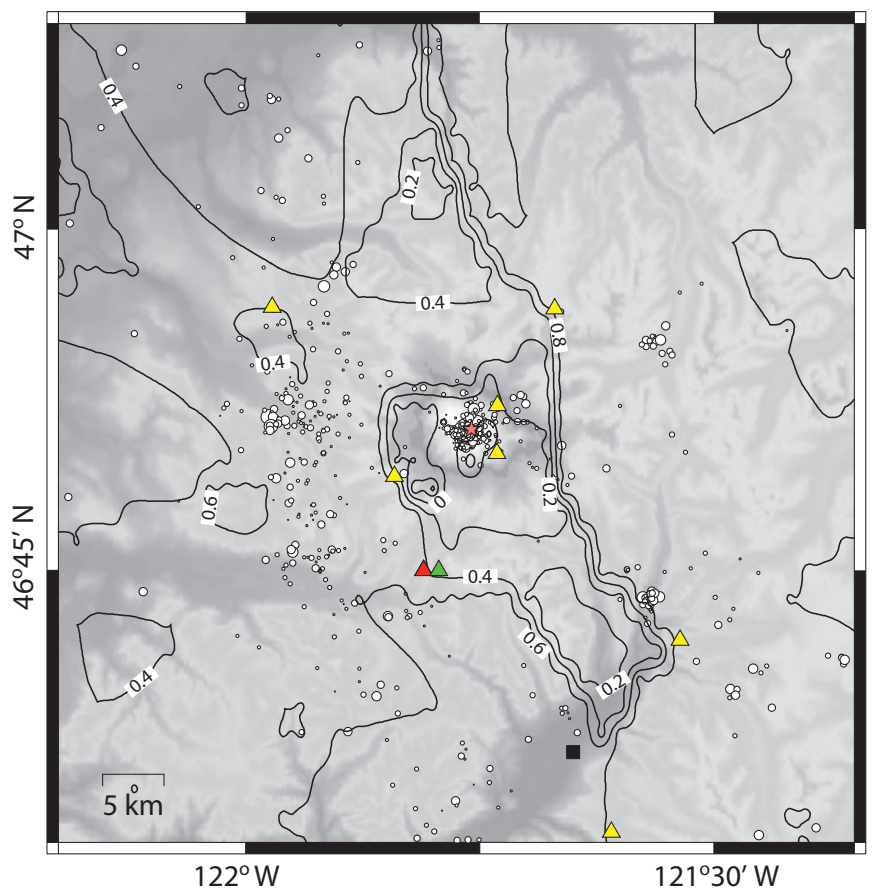

Figure 33. Contours of magnitude thresholds for "good" locations at Mount Rainier.

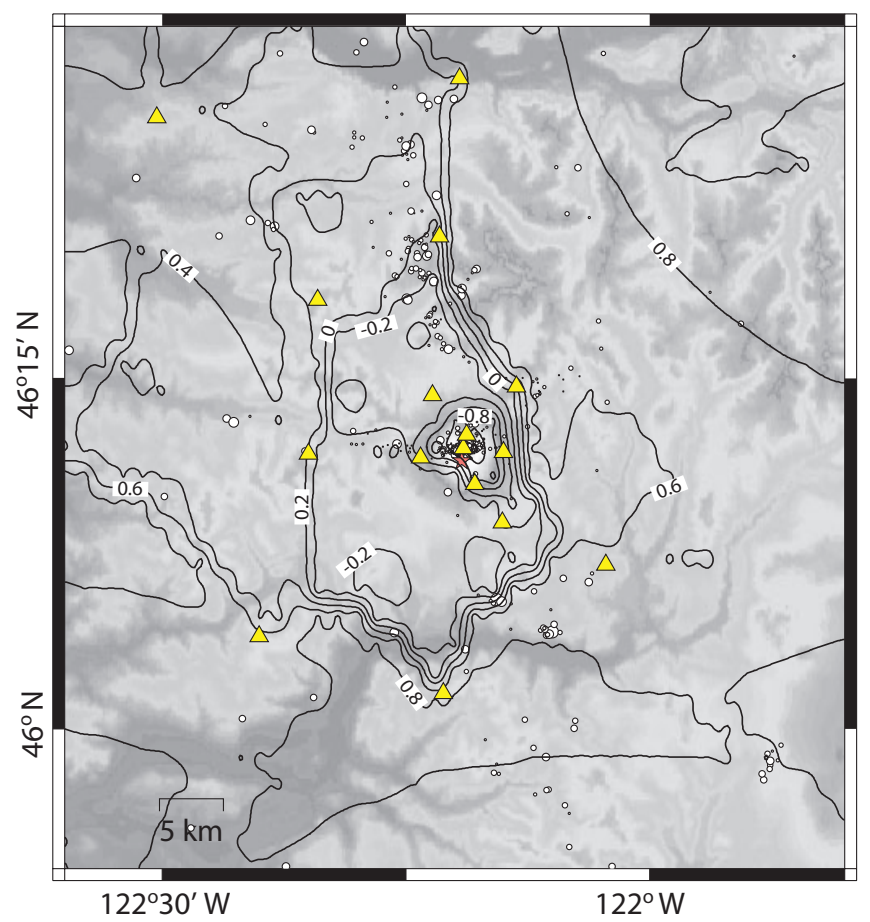

Figure 34. Contours of magnitude thresholds for "good" locations at Mount St. Helens. 


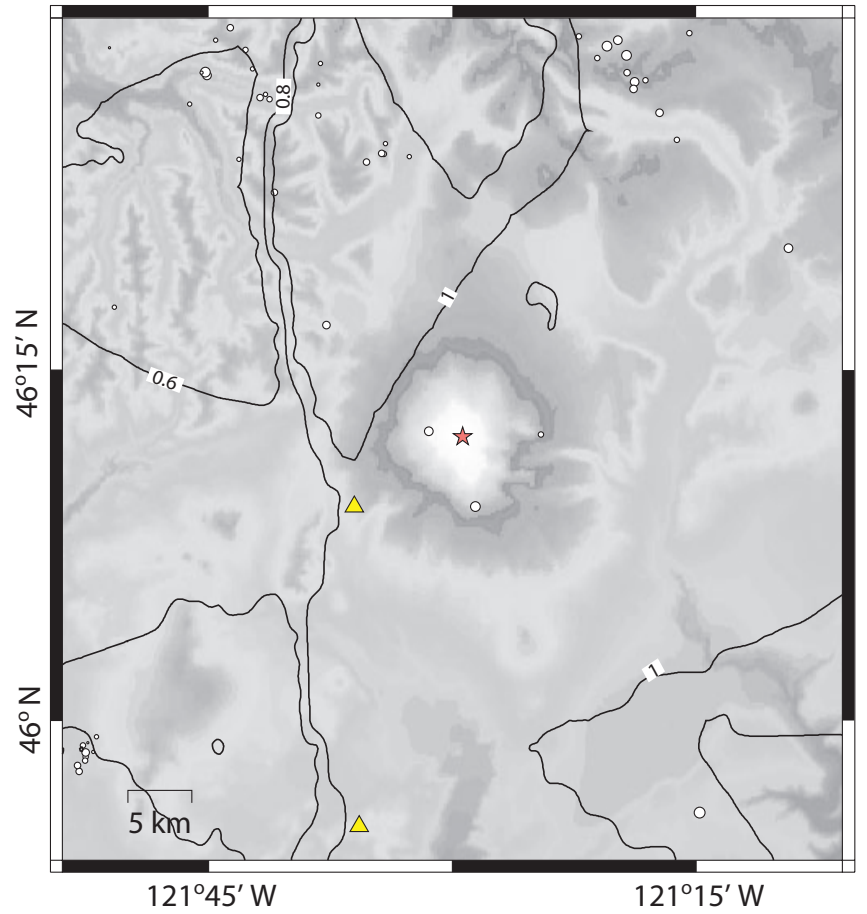

Figure 35. Contours of magnitude thresholds for "good" locations at Mount Adams.

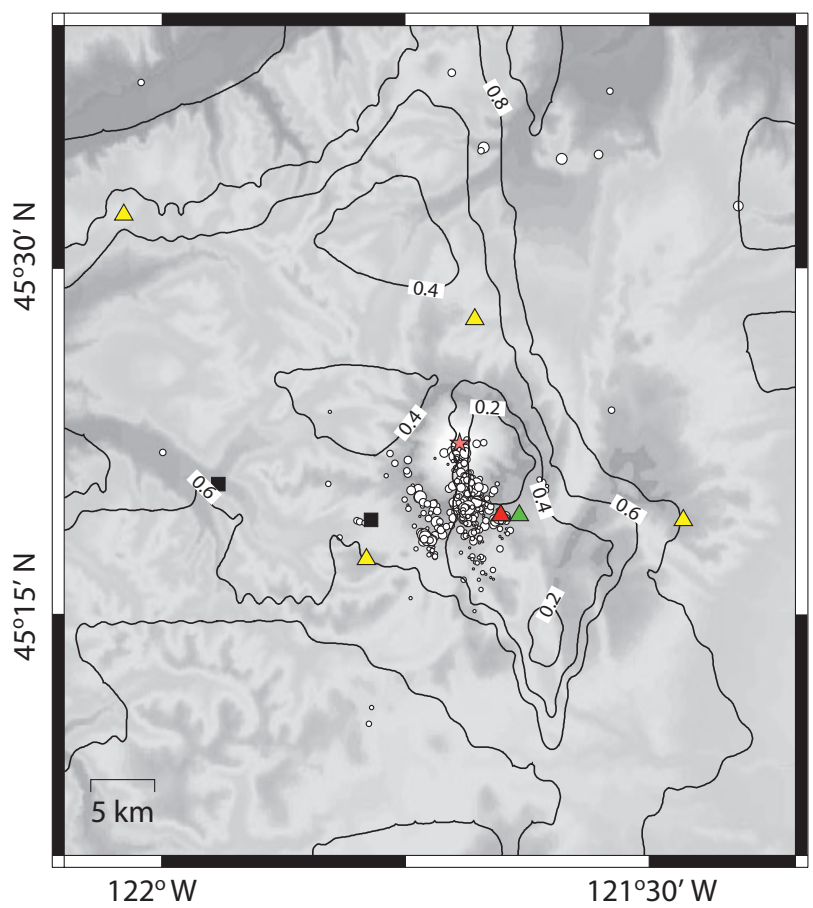

Figure 36. Contours of magnitude thresholds for "good" locations at Mount Hood.

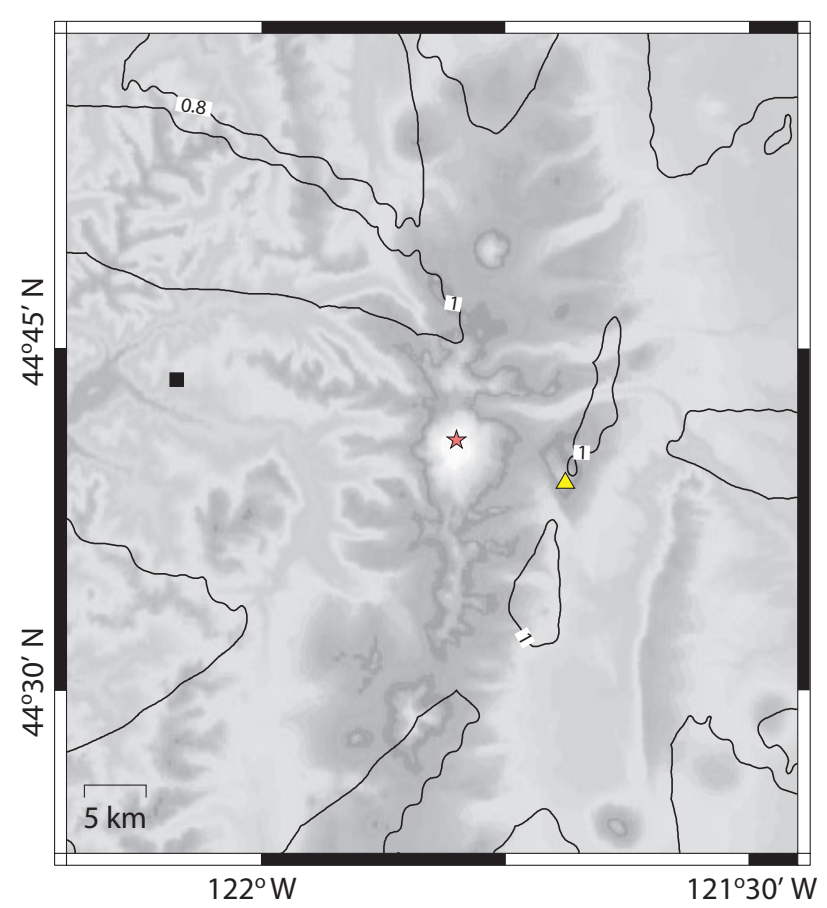

Figure 37. Contours of magnitude thresholds for "good" locations at Mount Jefferson.

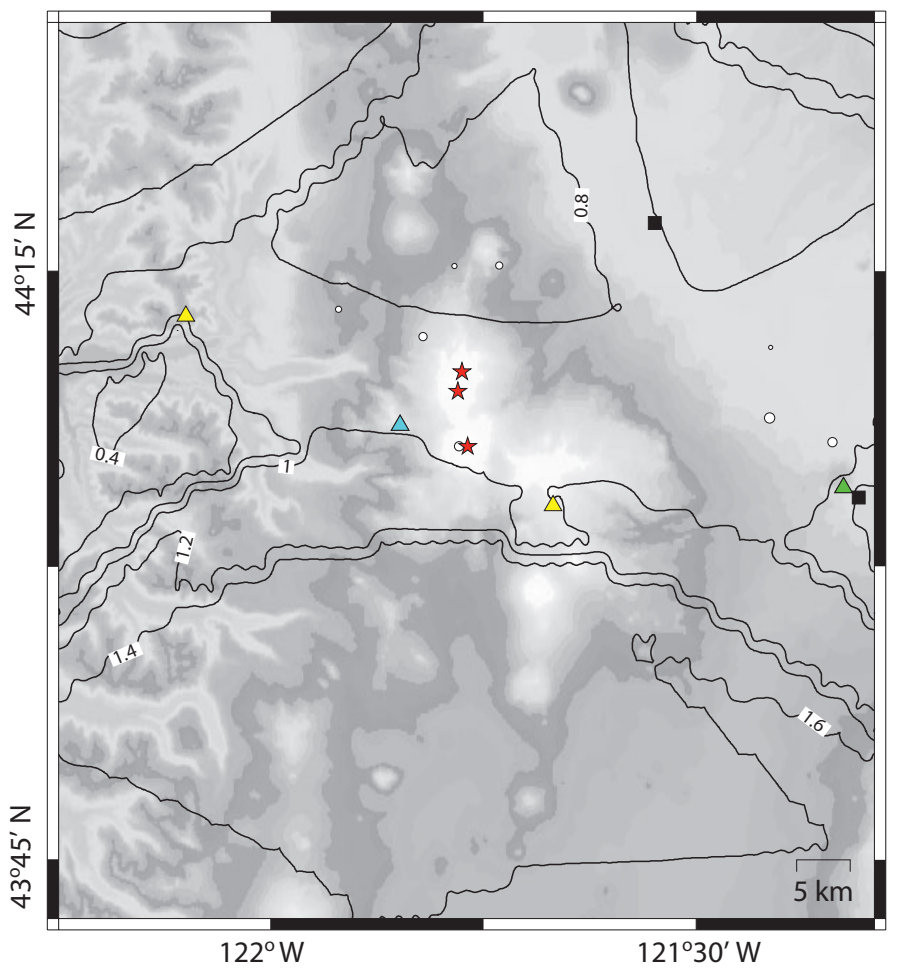

Figure 38. Contours of magnitude thresholds for "good" locations at Three Sisters. 


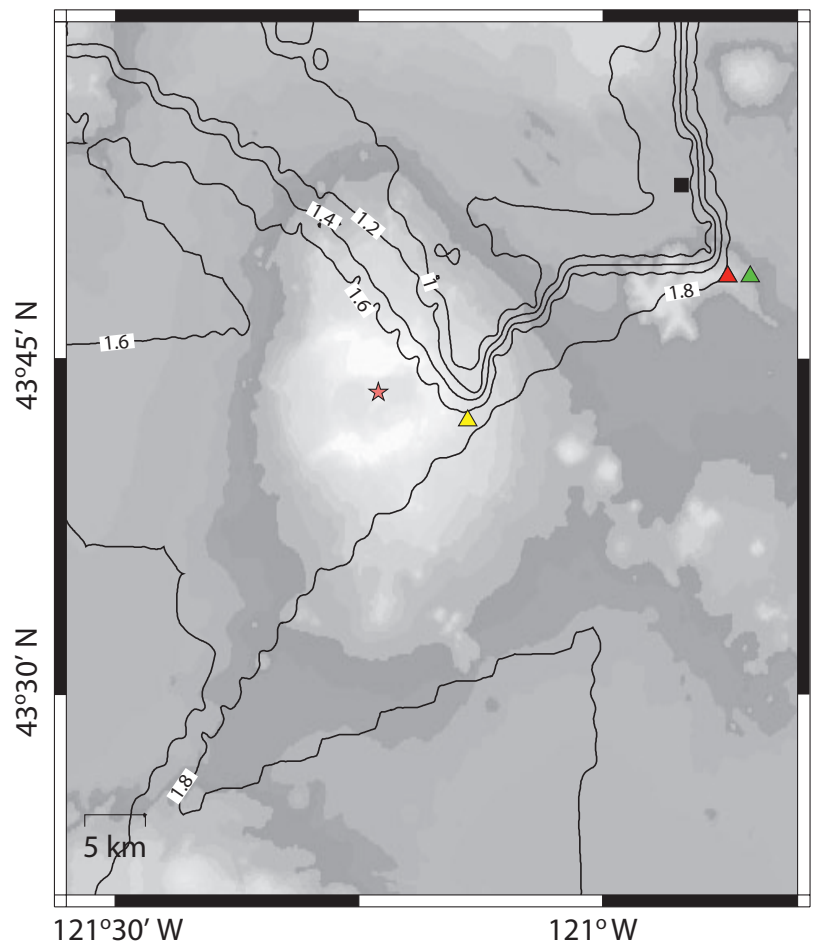

Figure 39. Contours of magnitude thresholds for "good" locations at Newberry Volcano.

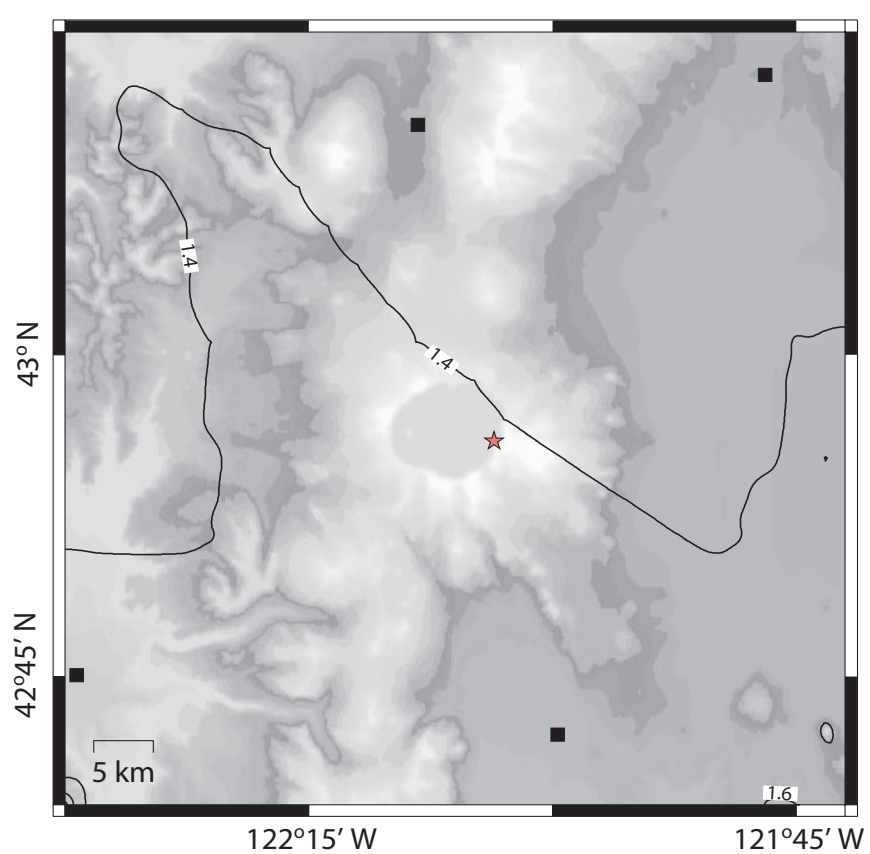

Figure 40. Contours of magnitude thresholds for "good" locations at Crater Lake.

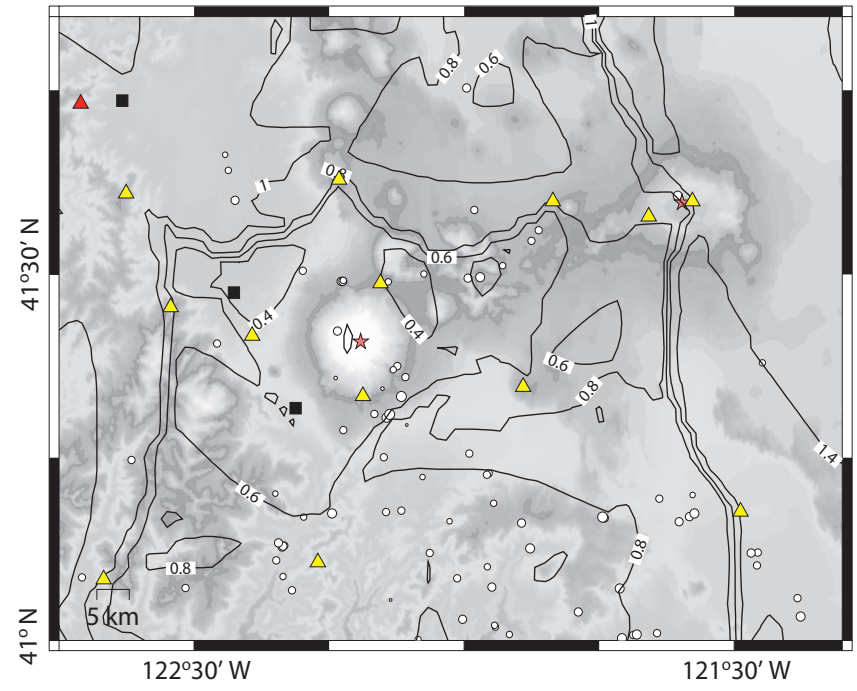

Figure 41. Contours of magnitude thresholds for "good" locations at Mount Shasta and Medicine Lake.

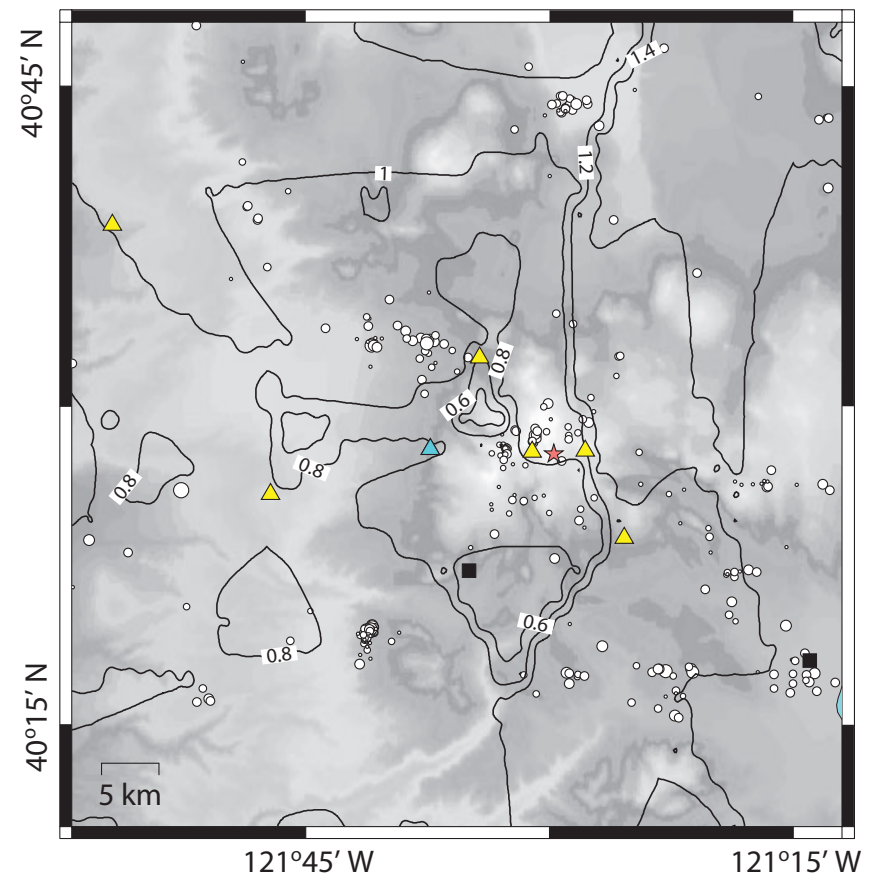

Figure 42. Contours of magnitude thresholds for "good" locations at Lassen Peak. 
determinations; (2) determining particle motions, which can be used to estimate locations of tremor sources (for example, see Arciniega-Ceballos and others, 2003) as well as phase identification for non standard events (for example, see White, 1996); and (3) potentially determining moment-tensor solutions, which are important for assessing whether sources have a volumetric (explosive or implosive) component (for example, see Julian and others, 1998). Broadband instruments are necessary for detecting VLP events (Hill and others, 2002; Chouet and others, 2003) and tremor with dominant frequencies $<1$ $\mathrm{Hz}$, as well as greatly facilitating the computation of moment tensors (for example, see Chouet and others, 2003). Digital stations (on-site digitizers and digital telemetry) are necessary for providing wide dynamic range, enabling stations to be sensitive enough to record small events and to also stay on scale during energetic events such as large earthquakes or eruptions. Finally, for tremor identification, which is often accomplished through visual cross-correlation, having several stations in the near-field is vital for distinguishing between low-amplitude tremor (see fig. 43) and wind or other noise sources.

One additional consideration is that near-field microphones (or infrasonic recorders) have proven useful in determining whether or not explosions are occurring and constraining the depth of such sources. Microphones are not vital for monitoring networks on dormant volcanoes, but they should be considered in any monitoring effort on restless or erupting volcanoes.

\section{5-Recommendations}

\section{1-Seismic networks should be upgraded before any unrest occurs}

The March 23-25 swarm in 2004 at Three Sisters illustrated the importance of having an adequate seismic network installed before any unrest occurs. In March 2004 the Three Sisters seismic network consisted of two stations within 20 $\mathrm{km}$ of the Three Sisters edifices, one of which was offline and the other intermittent due to telemetry interference from an above-average snow pack, and three others within $50 \mathrm{~km}$. This network was sufficient for detecting the swarm and for locating earthquakes as small as $\mathrm{M}_{\mathrm{L}}=-0.1$. However, of the more than 300 events that occurred, only 73 were recorded on enough stations to allow for a location, and only 11 of the locations had gaps of $<135^{\circ}$ and thus, by one measure, had "well-constrained" epicenters. Furthermore, because of the loss of station HUO (see fig. 10) the nearest operating station was MOON at $\sim 14 \mathrm{~km}$, and, as a result, depths were poorly constrained. Even if station HUO had been in operation, the east-west planar alignment of the five closest stations would still have resulted in few "good" locations, as most of the swarm earthquakes occurred north of this planar alignment. In other words, the network in place was sufficient for detection, but not location. This meant that, among other things, any lateral or vertical migration of hypocenters with time was undetectable.
Had the swarm continued, installation of new telemetered stations near the source would have been difficult and timeconsuming due to winter conditions and the time required to establish new communication channels to transmit data from new stations in real time. With snow depths of 5 to 10 feet in many places, the only quick way to access sites close to the swarm (which occurred entirely within the Three Sisters Wilderness) is by helicopter, requiring at least 24 hours to make necessary arrangements (if an available nearby helicopter can be found) and good weather. Telemetering signals also requires site visits to repeaters and receiving nodes, as well as having available slots on phone or microwave circuits. Thus had the swarm continued, it would have taken at least several days to establish new telemetered sites near the swarm and several days before well-constrained locations could have been determined. This further demonstrates that, particularly for sites close to a volcanic system, it is critical to have sufficient numbers of telemetered stations installed well before any seismic unrest. Once unrest occurs, it may be difficult or impossible to install sufficient numbers of seismometers to effectively monitor a restless volcano.

In the next section, I review the status of seismic networks at each of the 13 Cascade volcanic centers. The primary goal is to identify weaknesses in these networks that require installation of additional stations (before unrest occurs) to ensure a baseline capability exists at each center for detecting seismic unrest.

\section{2-Priority A volcano networks}

Of all the Cascade volcanoes, Mount Baker, Newberry Volcano, Medicine Lake, and Crater Lake have the poorest network coverage. The first three are problematic because, unlike all other Cascade volcanoes, they lie at or very near a margin of the PNSN/NCSN combined network and thus have at least one sector in which earthquakes of any magnitude cannot be located reliably without use of distant $(>150 \mathrm{~km})$ non-PNSN/NCSN stations. They also have few near-field stations $(<10 \mathrm{~km}$ from the presumptive vent), making our ability to detect unrest extremely vulnerable to station outages. Although Crater Lake is mostly surrounded by PNSN stations, none are closer than $45 \mathrm{~km}$, giving Crater Lake the worst detection threshold of all Cascade volcanoes. Three Sisters is also included as a Priority A volcano because, although it has a network with two near-field stations already in place, the years-long deformation, the poorly located March 23-25, 2004, seismic swarm, and the large geographical area in which an eruption could occur strongly argue for placing a high priority on improving detection and location capabilities.

\subsection{1—Mount Baker}

Mount Baker lies at the northern PNSN margin. It has one near-field station and three stations within $40 \mathrm{~km}$, including 


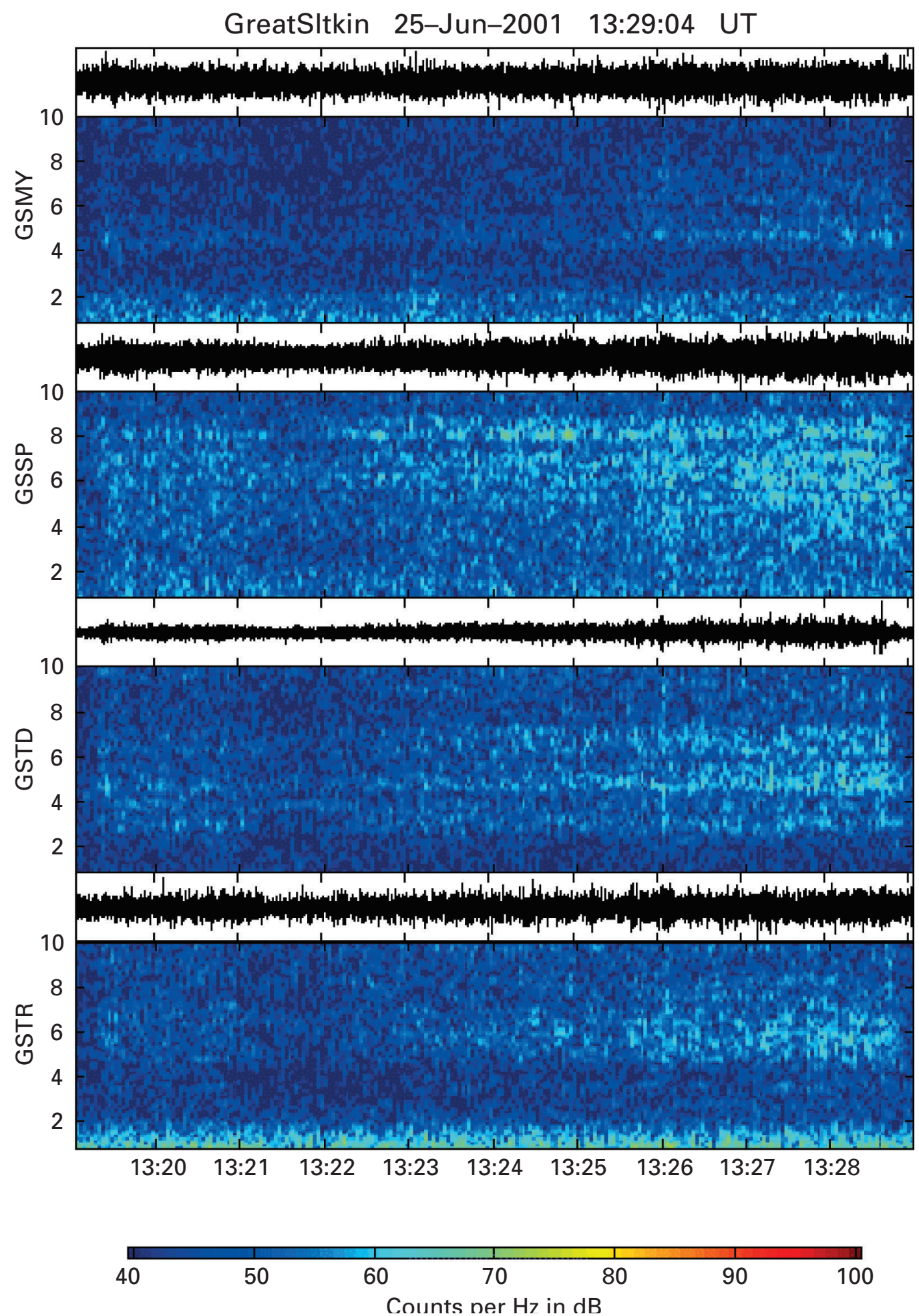

Figure 43. Multistation spectrogram showing a minutes-long tremor episode at Great Sitkin Volcano, Alaska. 
one in Canada (VDB). In Canada there are two stations north and east of Mount Baker; VDB (34 km to the northwest (fig. 44)) and PNT (172 km to the east-northeast). Data from these stations are shared in real-time with the PNSN, effectively expanding the PNSN aperture into Canada.

Since Mount Baker has a sparse network and is at the northern margin of the PNSN, it has significantly limited detection and location capabilities. These limitations include:

- For much of the northeast sector of the Baker edifice the gap between the two Canadian stations is $>135^{\circ}$, meaning that well-constrained locations from PNSN stations alone are impossible to achieve for much of the northeast sector (fig. 44) unless events are large enough to be located by the National Earthquake Information Center $(\mathrm{M} \sim 3.5-$ 4.0):

- With only three stations within $40 \mathrm{~km}$, the "good" location threshold is unacceptably high on all sectors of the edifice ( $\mathrm{M} \sim 1.7$; see fig. 44).

- Earthquake detection at Baker is highly dependent upon the single near-field station (MBW), which counts twice in the PNSN automated triggering algorithm. If MBW is offline (as was the case for most of the 2003-2004 winter), detection thresholds are significantly degraded, as the next nearest station is $28 \mathrm{~km}$ from the summit.

- With just one near-field station, tremor detection capabilities are also severely compromised.

To address these shortcomings, at least three stations should be added to the Baker network (fig. 44); one located north of Baker as close as possible to the summit (to provide another near-field station), another $15 \mathrm{~km}$ northeast of Baker (to make it possible to reliably locate $\mathrm{M} \geq 1.0$ earthquakes within $10 \mathrm{~km}$ of the edifice), and a third within $10-15 \mathrm{~km}$ on the southern or southeastern flank (to lower the "good" location threshold to $\mathrm{M} \sim 0.5$ at the summit itself). The resultant network would still be somewhat vulnerable to single-station outages, and its sparsity would likely not allow for reliable tracking of hypocenter migrations. Future improvements should include making arrangements for installation of at least one more station to the north-northeast of Baker in Canada.

\subsection{2-Newberry Volcano}

Newberry Volcano lies at the eastern margin of the PNSN. It has one near-field station and one broadband located $30 \mathrm{~km}$ to the east-northeast. The next nearest eastern station lies in Idaho, the next nearest southeastern station lies $255 \mathrm{~km}$ away in southeastern Oregon, and the nearest station to the south is $164 \mathrm{~km}$ away in Klamath Falls, Oregon. There is thus a risk that large events occurring off the southeastern flank of Newberry could not be reliably located. With only one near-field station, event detection capabilities are very vulnerable to single-station outages.

To address these shortcomings, two stations should be added, one to the east-northeast and one to the southsoutheast, both 10 to $20 \mathrm{~km}$ from the caldera. A third station installed within the caldera would provide redundancy, greatly improve detection thresholds and improve our ability to detect tremor, and provide better depth constraints for shallow intracaldera seismic events.

\subsection{3-Medicine Lake}

Medicine Lake lies at the eastern margin of the NCSN. There are two near-field stations, with the next nearest eastern station lying $\sim 260 \mathrm{~km}$ to the east-northeast in southeastern Oregon. There are also relatively few stations to the north (the nearest lies $\sim 64 \mathrm{~km}$ away in Klamath Falls, Oregon). As a result, there is a $\sim 180^{\circ}$ swath covering most of the eastern half of the edifice where earthquakes cannot be located reliably below M 1.4 (fig. 41). With only two near-field stations, earthquake detection is also highly vulnerable to station outages. Finally, the NCSN uses a five-station trigger for an event to be automatically detected, resulting in a high detection threshold even with both near-field stations functioning. All of these factors give Medicine Lake the second-worst theoretical detection threshold in the Cascades (M 1.0; see fig. 4).

To address these shortcomings, at least two stations should be added 5 to $15 \mathrm{~km}$ north and east of Medicine Lake.

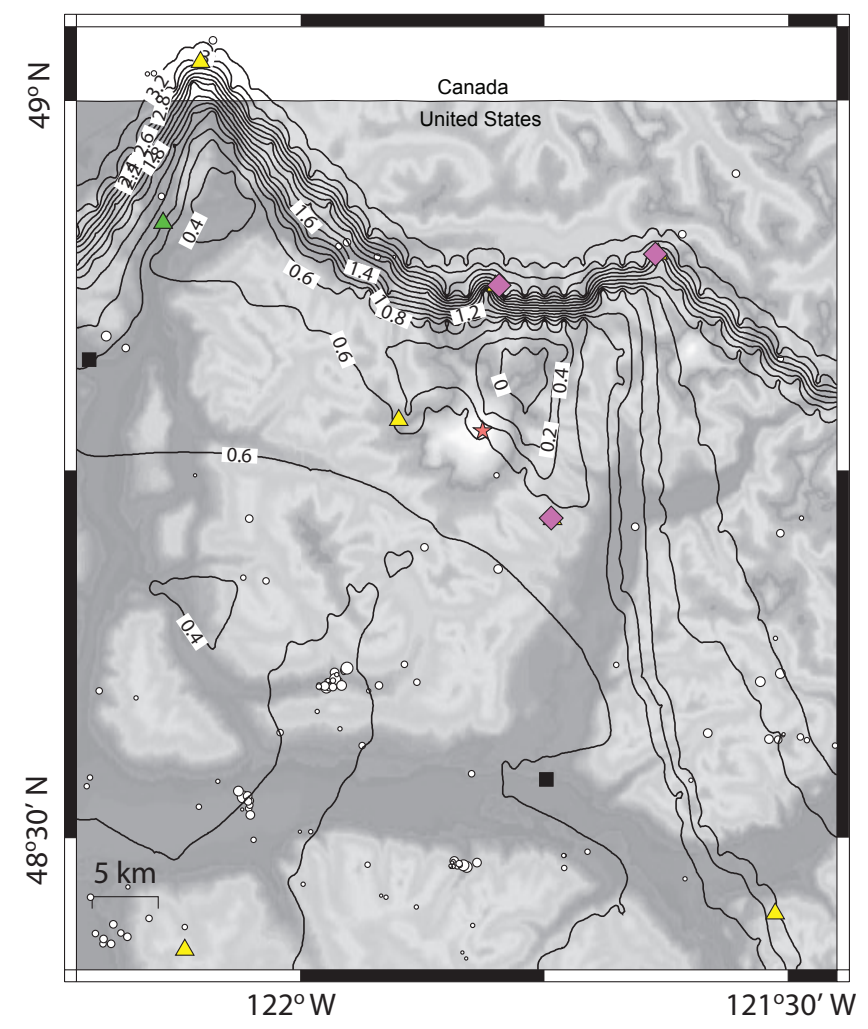

Figure 44. Contours of magnitude thresholds for "good" locations at Mount Baker network with three additional stations (pink triangles). Extreme wobbliness in contours north of Baker is an artifact of tight contour spacing and an inexact contouring program. 
In addition, detection thresholds would be greatly improved by lowering the NCSN trigger threshold from five stations to (ideally) three (for comparison, the Three Sisters network has a two-station trigger threshold). As with Baker, two new stations will greatly improve the ability to detect and roughly locate earthquakes in all sectors of the volcano, although location quality will still be marginal for small events.

\subsection{4-Crater Lake}

With no near-field stations and the nearest station $46 \mathrm{~km}$ distant, Crater Lake has the worst detection threshold (M 1.1; see fig. 4) of all Cascade volcanoes. Earthquake detection and location are entirely dependent upon PNSN regional stations. The lack of any near-field stations also means that tremor would be extremely difficult to detect unless it was very energetic.

Installing just one station will not improve this situation, as automatic detection requires at least two near-field stations (the PNSN currently employs a 2-station trigger at Three Sisters). In addition, at least two stations are required to distinguish between low-level seismic tremor and other noise sources (see fig. 43). However, ideally three stations should be installed, as a third near-field station would provide a safety margin in case of station outages and would yield a much better network geometry. A 3-station network would still likely not be able to provide "good" locations for events too small to show up on regional stations $(\mathrm{M} \leq \sim 1)$ or track hypocenter migrations very reliably, but it would be infinitely better than no network at all.

\subsection{5-Three Sisters}

As discussed above, the March 23-25, 2004, seismic swarm demonstrated that location capabilities of the current Three Sisters network are not good, even with the nearest station (HUO) in operation. Since the swarm one new station has been added to the north near Black Crater, and three more stations will be installed in the summer of 2004 at The Wife, near Two Buttes to the northwest, and near Trout Creek Butte to the east (magenta diamonds in fig. 45). These four new sites will greatly improve the situation for the area around the "bulge" and March 23-25 swarm (see fig. 45 for revised location thresholds with these four stations in place). After these new sites are in place the Sisters network will include two threecomponent short-period and two broadband sites, making it the most modern network operated at a Cascade volcano.

However, this improved network will still have serious deficiencies. One can be seen in fig. 45; the "good" location threshold along the Three Sisters themselves will be $\mathrm{M} \sim 0.2-$ 0.4 , but will degrade markedly to the north of North Sister and spectacularly south of South Sister. The location threshold ideally should be $M \leq 0$ over the entire area where future eruptions could occur, a 20 by 30 kilometer swath that surrounds the Three Sisters (W. E. Scott, oral commun., 2004). In addition, at least one near-field station is needed near North Sister to ensure well-constrained depths should future seismicity occur north of the March 23-25 swarm area. These two deficiencies require installation of at least four more stations; two sites in the near-field near North Sister within the wilderness, and two others south of South Sister (fig. 46).

\section{3-Priority B volcano networks}

All other Cascade volcanoes lie within the broader PNSN/ NCSN network, providing a baseline ability to determine reasonably well-constrained locations for $\sim \mathrm{M}>1.5$ events within $\sim 10 \mathrm{~km}$ of the summit (fig. 30). However, Glacier Peak, Mount Adams, and Mount Jefferson networks have only one near-field station, and thus have only a relatively poor ability to locate small earthquakes and detect other types of seismic sources, in particular seismic tremor. Their detection and location capabilities are also vulnerable to outages of their sole near-field stations.

\subsection{1—Glacier Peak}

Despite installation of one very-near-field station (GPW) in 2001, detection capabilities at Glacier Peak are still poor. Glacier Peak is a noisy volcano, with GPW records dominated

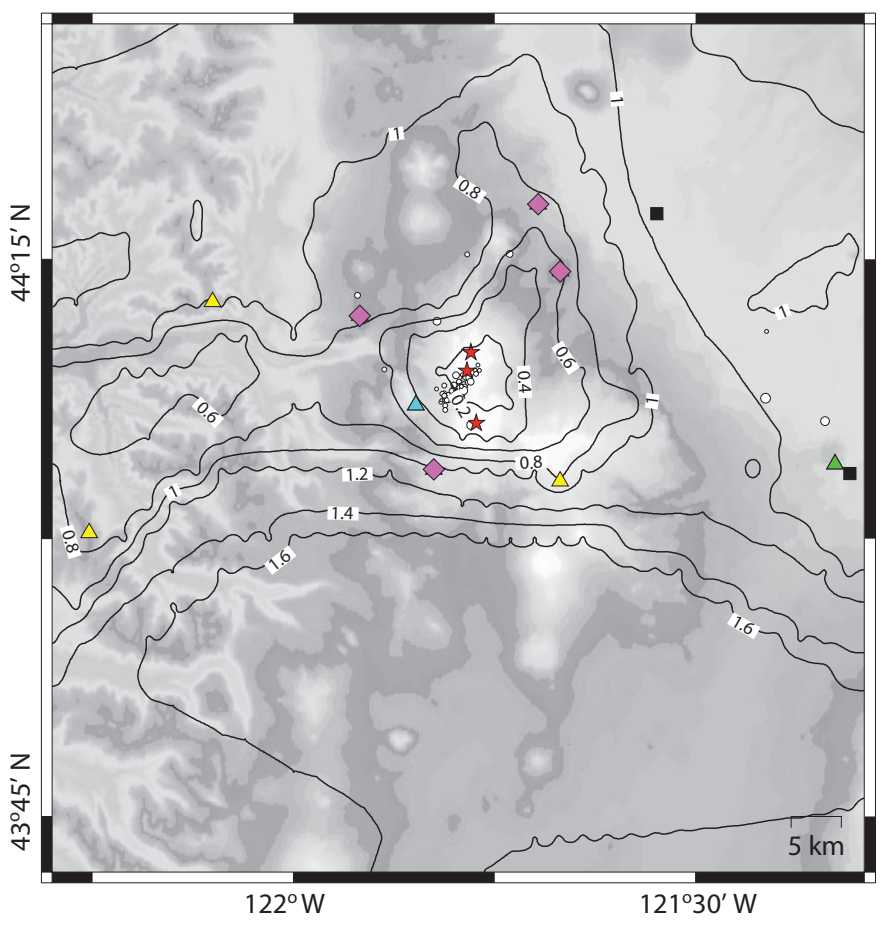

Figure 45. Contours of magnitude thresholds for "good" locations at Three Sisters with four additional stations (magenta diamonds) to be installed in 2004. 
by what are presumably glacier quakes that occur several times an hour. With only one near-field station and a nextnearest station $33 \mathrm{~km}$ to the southeast, it is impossible to determine whether any of these events are volcanic earthquakes of some sort. It would also be next to impossible to distinguish low-level tremor from wind noise. Another consideration is location; GPW is located high on a flank of Glacier Peak (necessary for data from it to be radioed directly to the University of Washington) and so is prone to weather-related outages in the winter (for example, it was damaged in the early spring of 2004 and remains off-line as of August 2004). This makes detection and location capabilities more vulnerable to a single point-of-failure than at other single-station volcanoes.

To address these shortcomings, at least one additional station should be installed within $20 \mathrm{~km}$ of Glacier Peak. Given the high glacier-related noise level seen on GPW, this site should be placed several kilometers away from the summit glaciers. Telemetry and wilderness access are problematic around Glacier Peak, perhaps more so than any other Cascade volcano. Installing another near-field station would likely also require installation of a repeater site. Given these limitations, it is perhaps most prudent to pursue a two-pronged approach: (1) Focus first on installing an intermediate-field (15-25 km) station outside of the wilderness that can be telemetered with relative ease. One possible site is $\sim 20$ west-northwest of Glacier Peak on the northwest flank of Pugh Mountain. This

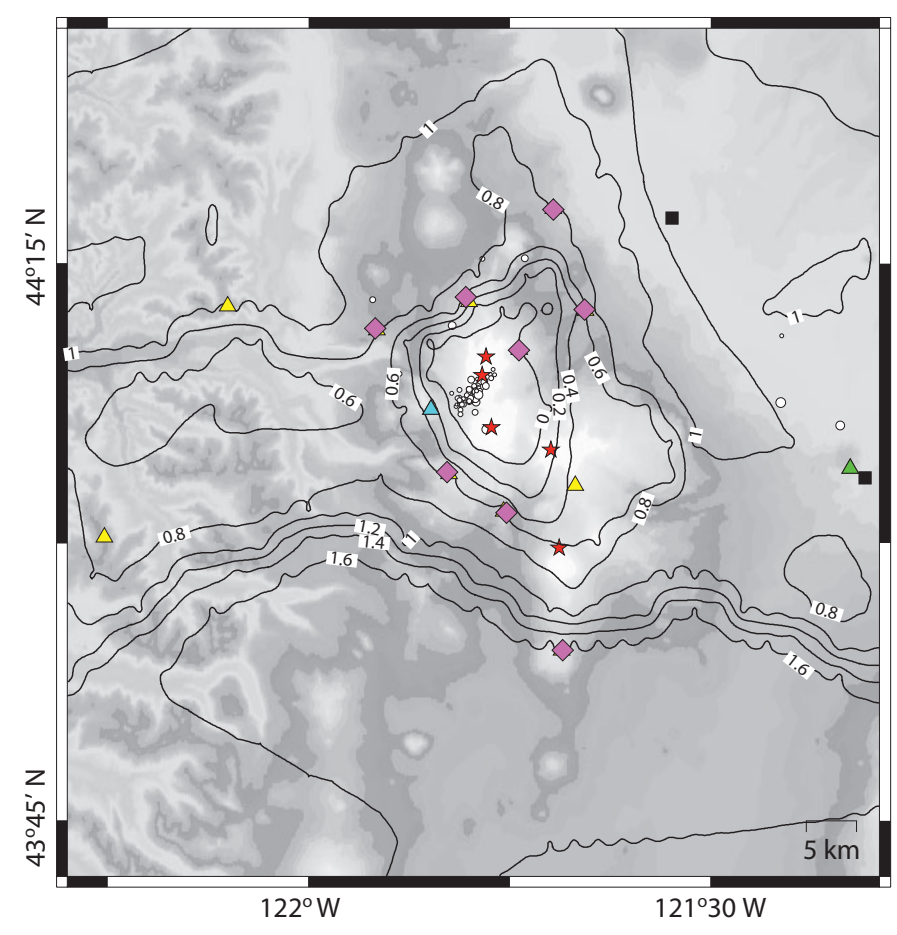

Figure 46. Contours of magnitude thresholds for "good" locations at Three Sisters with eight additional stations (magenta diamonds), four of which are scheduled to be installed in 2004. could be accomplished in a several-months time frame, assuming permits and equipment are readily attainable; (2) Begin the process of identifying a new near-field site and all of the telemetry path requirements, and, once a site is identified, begin the permitting process. This would likely take one to several years, based on past experience with the installation of GPW (C. A. Gardner, oral commun., 2004).

\subsection{2-Mount Adams}

Mount Adams has one station (ASR) that lies $\sim 11 \mathrm{~km}$ to the west, with the next-nearest station $33 \mathrm{~km}$ to the southsouthwest near the Washington/Oregon border. The St. Helens network to the west and the Mount Hood network to the south bolster detection and location capabilities. The lack of a nearfield station means that depth determinations are compromised, as are tremor detection capabilities. These issues can be addressed by addition of one near-field station, ideally on the eastern side of the volcano.

\subsection{3-Mount Jefferson}

Mount Jefferson also has only one near-field station (BPO), with the next-nearest station located $44 \mathrm{~km}$ to the north. Detection capabilities are marginally bolstered by the Mount Hood network to the north and the presently expanding Three Sisters network to the south. Nevertheless, Mount Jefferson has the third-worst theoretical detection threshold (M 0.9) of all Cascade volcanoes, illustrating that detection of small earthquakes and tremor is compromised by presence of only one near-field station. To address these issues, at least one additional near-field station should be installed, ideally on the west side.

\section{4-Priority C volcano networks}

Networks at the other Cascade volcanoes (Mount Rainier, Mount St. Helens, Mount Hood, Mount Shasta, and Lassen Peak) have enough stations near the summits to enable adequate detection, although not necessarily adequate location, of seismic unrest, as well as to be less vulnerable to single-station outages. However, none are ideal, even Mount St. Helens. For example, only three volcanoes have a digital station nearby (Rainier, Hood, and Newberry), meaning that most networks will "clip" during any energetic event, resulting in loss of information vital both for monitoring and research into the nature of eruptive processes. In addition, only five volcanoes have a three-component station nearby (Rainier, Hood, Three Sisters, Newberry, and Lassen). This means that, amongst other things, tremor sources cannot be located (which requires many (8 to 10) three-component stations). In addition to these limitations, other improvements described below should be made at some point to each network. 


\subsection{1-Mount Rainier}

Mount Rainier has three near-field stations and six within $20 \mathrm{~km}$ of the summit. In addition, it is one of two volcanoes to have a broadband close to the summit (LON). However, two of the near-field stations (RCM and RCS) are at high altitudes and are particularly prone to winter-weather-related outages. Another problem is that the five nearest stations are aligned in a NE-SW direction (fig. 5), which can increase location errors for events locating to the northwest or southeast. Improvements to be made at Rainier include improving the robustness of RCS and RCM, perhaps by putting them in more robust enclosures, and installing an additional site near or on the northwest flank of Rainier.

\subsection{2-Mount Hood}

Mount Hood has two stations in the near-field, including one broadband (the only Cascade volcano with a near-field broadband). However, the "good" location threshold is only $\sim 0.4$ over the entire western flank of Hood and drops off markedly east of the Hood River, a result of there being only four stations within $30 \mathrm{~km}$ of the summit. To address these shortcomings two additional seismometers should be added, one on the northwest flank of Hood (ideally within $10 \mathrm{~km}$ of the summit), the other east-northeast of the summit (ideally 10-15 $\mathrm{km}$ of the summit).

\subsection{3-Mount Shasta}

Mount Shasta has two near-field stations and six within 30 $\mathrm{km}$ of the summit. Furthermore, detection and location capabilities benefit greatly from Shasta being located within a relatively dense network of regional stations. However, none are closer than $8 \mathrm{~km}$ to the summit, meaning that depth constraints may not be sufficient to enable detection of hypocentral migration in the uppermost several kilometers (including most of the edifice, which lies above the two closest seismometers). Also, the sheer size of the Shasta edifice means that more stations are needed to lower the good location threshold from the current $\mathrm{M} \sim 0.4$ down to $\mathrm{M} 0.0$. To address these shortcomings, at least one station should be added near the summit. The detection threshold ( $\mathrm{M} \sim 0.4$ ) could also be lowered if the NCSN reduced its trigger requirement for automatic event detection from five to three or four stations.

\subsection{4-Lassen Peak}

Lassen Peak volcano has three near-field stations and six within $30 \mathrm{~km}$ of the summit. Because of this network geometry, the detection threshold is quite good at Lassen. However, the "good" location threshold is $\mathrm{M} \sim 0.9$ at the summit (fig.
42), a result of the east-west alignment of the six nearest stations and the lack of nearby stations east-northeast of Lassen. This could be addressed by adding one station $\sim 10 \mathrm{~km}$ northeast of Lassen. Placing a second new station $\sim 10 \mathrm{~km}$ to the southwest would further improve network geometry. Finally, reducing the NCSN's current five-station trigger requirement for automated detection to three or four stations is a cheap and easy way to lower detection thresholds even further without installing new stations.

\section{5-Priority D volcano networks}

\subsection{1-Mount St. Helens}

Mount St. Helens has eight near-field stations and thirteen within $20 \mathrm{~km}$ of the lava dome. This is the densest network operating in the Cascades with the best detection and location thresholds, and can withstand simultaneous outages of several stations with minimal impact on detection and location capabilities. It would be an even better network if it had another station $10-20 \mathrm{~km}$ to the northeast, as location capabilities in this sector are currently vulnerable to the loss of station SOS, the only northeast-sector station outside of the crater. Another issue is that the network is in need of modernization. All stations are short-period vertical-component sites; at least a few should be considered for upgrades to three-component and (or) broadband sites.

\section{6-Conclusions}

All Cascade volcano networks have shortcomings compared to modern-day networks operated at, for example, Mount Etna in Sicily, where activity is monitored by $~ 35$ short-period stations, eight broad-band stations (telemetered using satellite uplinks), and three short-period three-component stations (fig. 47). In the face of limited resources, however, installation of modern-day networks at one or more of the thirteen Cascade volcanic centers is at present highly unlikely.

Instead, this report has focused on relatively inexpensive and (mostly) easy-to-achieve improvements that are needed to enable or improve baseline detection and interpretation of seismic unrest. Volcano networks most in need of additional seismometers include Mount Baker, Three Sisters, Newberry Volcano, Crater Lake, and Medicine Lake:

- Crater Lake is essentially unmonitored in the sense of being able to detect small $(\mathrm{M}<1)$ magnitude earthquakes and low-amplitude tremor. At least two stations should be installed on or near the rim.

- Mount Baker, Newberry Volcano, and Medicine Lake are all at the edge of the PNSN/NCSN network, and as a result even moderate-sized (M 2.0 or larger) earthquakes can fall outside of the network and be poorly located. 
Each of these networks requires at least one, preferably two, optimally placed stations to solve this.

- The March 23-25, 2004, swarm at Three Sisters demonstrated that the Sisters network is capable of detecting small earthquakes but is not able to locate them very well. The current unrest argues for significantly improving detection and location capabilities now to ensure that future seismicity will be detected and located well enough to allow for relatively unambiguous interpretations.

In addition to these five networks, three other networks (Glacier Peak, Mount Adams, and Mount Jefferson) have only a single near-field station. Installation of at least one, and preferably two, new stations near each of these volcanoes would yield significant improvements in detection thresholds. It would also greatly reduce the dependence of our monitoring capabilities at these volcanoes on a single station and our consequent vulnerability to weather-related or other types of outages.

Mount Rainier, Mount Hood, Mount Shasta, and Lassen Peak volcanoes all have reasonable networks in place that should be able to detect most types of volcano-related seismicity. However, all have weaknesses that are readily addressable via changes in trigger thresholds (Shasta, Lassen Peak) and (or) by additions of one or two stations. Finally, Mount St. Helens is the only Cascade volcano with a seismic network that, other than a wholesale upgrade to modern equipment, requires no new seismic stations.

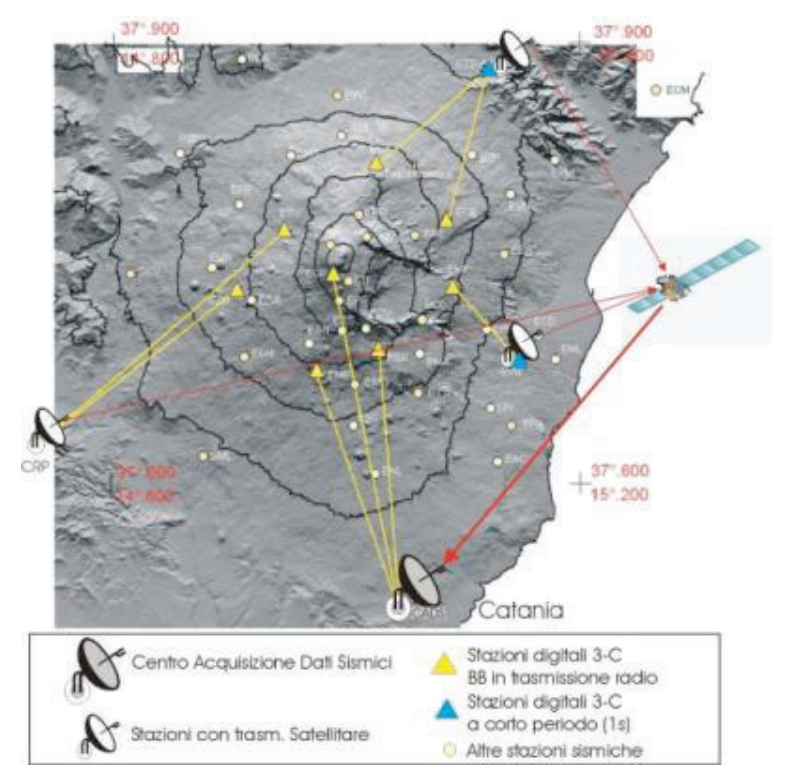

Figure 47. Seismic monitoring network around Mount Etna, Italy (image from the Istituto Nazionale di Geofisica e Vulcanologia (Catania) web site (URL: http://www.ct.ingv. it/Sismologia/images/Rete_Satellitare.jpg)).

\section{Acknowledgments}

Bobbie Myers modified and significantly improved the PNSN/NCSN network figure shown on the front page. Elliot Endo, David Hill, Willie Scott, and Jeff Wynn gave detailed comments that significantly improved the clarity and presentation of this report, and final edits by Jim Hendley improved readability and ensured consistency throughout. David Oppenheimer provided information on NCSN triggering thresholds, and Steve Malone gave the same for the PNSN. Both also gave valuable feedback on the theoretical detection and "good" location thresholds presented in this report. All mapview figures were generated using Generic Mapping Tools (GMT) software (Wessel and Smith, 1991).

\section{References}

Arcieniega-Ceballos, A., Chouet, B., and Dawson, P.2003, Longperiod events and tremor at Popocatepetl Volcano (1994-2000) and their broadband characteristics: Bulletin of the Seismological Society of America, v. 65, no. 2-3, p. 124 to 135.

Bittenbinder, A. N., Bogaert, B.M., Johnson, C.E., and Malone, S.D., 1994, Earthworm; a modular distributed processing approach to seismic network processing (abs.): Seismological Research Letters, v. 65, no. 1, p. 51.

Chouet, B., Dawson, P., Ohminato, T., Martini, M., Saccorotti, G., Giudicepietro, F., De Luca, G., Milana, G., and Scarpa, R., 2003, Source mechanisms of explosions at Stromboli Volcano, Italy, determined from moment-tensor inversions of very-long-period data: Journal of Geophysical Research, v. 108 , no. B1, p. ESE 7-1 to 7-25.

Hill, D.P., Dawson, P., Johnston, M.J.S., Pitt, A.M., Biasi, G., and Smith, K., 2002, Very-long-period volcanic earthquakes beneath Mammoth Mountain, California: Geophysical Research Letters, v. 29, no. 10, p. 8-1 to 8-4.

Julian, B.R., Miller, A.D., and Foulger, G.R., 1998, Non-doublecouple earthquakes 1. Theory: Reviews of Geophysics, v. 36, no. 4 , p. 525 to 549 .

Wessel, P., and Smith, W.H.F., 1991, Free software helps map and display data: EOS, v. 72, p. 441, 445-446.

White, R. A., 1996, Precursory deep long-period earthquakes at Mount Pinatubo - spatio-temporal link to a basalt trigger, in Fire and Mud - Eruptions and Lahars of Mount Pinatubo, Phillipines, C. G. Newhall and R. S. Punongbayan, eds.: Philippine Institute of Volcanology and Seismology and University of Washington Press, p. 307 to 328. 